Article

\title{
The Effect of Supplemental Irrigation on Canopy Temperature Depression, Chlorophyll Content, and Water Use Efficiency in Three Wheat (Triticum aestivum L. and T. durum Desf.) Varieties Grown in Dry Regions of Jordan
}

\author{
Abdul Latief A. Al-Ghzawi ${ }^{1, *}$, Yahya Bani Khalaf ${ }^{2,3}$, Zakaria I. Al-Ajlouni ${ }^{2}$, \\ Nisreen A. AL-Quraan ${ }^{4}$, Iyad Musallam ${ }^{3}$ and Nabeel Bani Hani ${ }^{3}$ \\ 1 Department of Biology and Biotechnology, Faculty of Science, The Hashemite University, P.O. Box 330127, \\ Zarqa 13133, Jordan \\ 2 Department of Plant Production, Faculty of Agriculture, Jordan University of Science and Technology, \\ Irbid 22110, Jordan; yahyawm@yahoo.com (Y.B.K.); ziajlouni@just.edu.jo (Z.I.A.-A.) \\ 3 National Center for Agricultural Research and Extension, Baqa', P.O. Box 639, Amman 19381, Jordan; \\ iyad@ncare.gov.jo (I.M.); nabeelbanihani@yahoo.com (N.B.H.) \\ 4 Department of Biotechnology and Genetic Engineering, Faculty of Science and Arts, Jordan University of \\ Science and Technology, Irbid 22110, Jordan; naquraan@just.edu.jo \\ * Correspondence: ghzawi@hu.edu.jo; Tel.: +962-795519765
}

Received: 20 February 2018; Accepted: 1 May 2018; Published: 4 May 2018

\begin{abstract}
One critical challenge facing the world is the need to satisfy the food requirements of the dramatically growing population. Drought stress is one of the main limiting factors in the wheat-producing regions; therefore, wheat yield stability is a major objective of wheat-breeding programs in Jordan, which experience fluctuating climatic conditions in the context of global climate change. In the current study, a two-year field experiment was conducted for exploring the effect of four different water regimes on the yield, yield components, and stability of three wheat (Triticum aestivum L.; T. durum Desf.) Jordanian cultivars as related to Canopy Temperature Depression (CTD), and Chlorophyll Content (measured by Soil-Plant Analysis Development, SPAD). A split plot design was used in this experiment with four replicates. Water treatment was applied as the main factor: with and without supplemental irrigation; $0 \%, 50 \%, 75 \%$, and $100 \%$ of field capacity were applied. Two durum wheat cultivars and one bread wheat cultivar were split over irrigation treatments as a sub factor. In both growing seasons, supplemental irrigation showed a significant increase in grain yield compared to the rain-fed conditions. This increase in grain yield was due to the significantly positive effect of water availability on yield components. Values of CTD, SPAD, harvest index, and water use efficiency (WUE) were increased significantly with an increase in soil moisture and highly correlated with grain yield. Ammon variety produced the highest grain yield across the four water regimes used in this study. This variety was characterized by the least thermal time to maturity and the highest values of CTD and SPAD. It was concluded that Ammon had the highest stability among the cultivars tested. Furthermore, CTD and SPAD can be used as important selection parameters in breeding programs in Jordan to assist in developing high-yielding genotypes under drought and heat stress conditions.
\end{abstract}

Keywords: canopy temperature depression (CTD); chlorophyll content; drought stress; supplemental irrigation; Triticum; water use efficiency (WUE) 


\section{Introduction}

Wheat (Triticum spp.) is one of the most essential food crops in the world [1-3]. Recently, wheat production has not met consumer demand, which results in hunger and price instability worldwide. In 2050, the demand for wheat is expected to increase by $60 \%$ with a predicted world population of 9 billion [4]. To meet the needs of a dramatically increasing population, annual wheat production must increase from the current level (below 1\%) to at least $1.6 \%$ [3]. Therefore, all agricultural policies must be directed toward enhancing wheat production by developing a global strategic agenda for wheat research, encouraging efficient investment in wheat research, and developing genotypes tolerant to both biotic and abiotic stress conditions-knowing that the available water reserves worldwide are limited and declining continuously [5-8].

Currently, wheat production in Jordan is not sufficient to cope with the needs of the Jordanian population and Syrian refuges. Achieving food security in Jordan depends on maintaining a reserve of this strategic crop. In Jordan, 24.7 thousand hectares were used to grow wheat with an average yield of 1.22 ton ha ${ }^{-1}$ during the period 2010 to 2014 [9]. The amounts of harvesting yield (25.1 thousand tons) were less than $3 \%$ of local consumption (916.4 thousand tons) during that period [9]. This will lead to increased wheat imports, which puts more pressure on Jordan's national budget. Therefore, the main priority of wheat research programs in Jordan is to enhance food security by increasing and stabilizing national wheat production. In Jordan, wheat was planted under rain-fed conditions with fluctuating precipitation within the season and between successive seasons, which led to poor crop cultivation success. Moreover, scientists predicted that Jordan, as a part of the Mediterranean region, will be subject to climate change, as indicated by increases in temperature and rainfall variability that would in turn increase drought and limit wheat yield production [10,11]. Annual precipitation around the Mediterranean region is likely to decrease by $4-27 \%$, which appears to be a typical response across global coupled climate models [11]. Such models have also predicted an increase of $3-5{ }^{\circ} \mathrm{C}$ in temperature [11] and around a $20 \%$ loss in soil moisture [12], supported by the fact that wheat production suffered from yield variability from year to year and from one location to another, caused by drought stress. Drought may occur pre-anthesis and negatively affect crop establishment and floret fertility $[13,14]$ or post-anthesis and adversely affect grain filling and grain development [15]. Therefore, improvement of wheat productivity under drought conditions became the main objective of the current breeding programs in arid and semi-arid regions.

Many studies indicated that water deficit at any developmental stage results in significant reductions in wheat yield and yield components. Such yield reduction will be larger if water deficit occurred during the tillering (GS20) and heading stages (GS60) [16,17]. However, other studies indicated that the sensitive stages are the milk-ripe (GS40) and booting stages (GS70) $[18,19]$. Grain yield has two components: number of grains $\mathrm{m}^{-2}$ (spikes $\mathrm{m}^{-2}$ and grains spike ${ }^{-1}$ ) and grain weight. Calderini et al. [20] demonstrated that wheat yield could be increased by selecting varieties with higher grains spike ${ }^{-1}$. Moreover, it has been reported that grains spike ${ }^{-1}$ is typically the yield component that is most sensitive to heat and drought stresses due to severe competition for nutrients during stem elongation [19,21-26]. In addition, post-anthesis drought caused earlier aging and a shortened grain filling duration [8].

Previous findings confirmed that the contribution of the morpho-physiological parameters in the adaptation of wheat depends on the intensity of the drought stress [27]. CTD and chlorophyll content measurements help breeders in investigating wheat yield stability since they are correlated with a number of adaptive physiological traits $[28,29]$. CTD is positively correlated with stomatal conductance [30], transpiration rate [5,31], water usage [30], leaf area index [32], root traits [33], and grain yield [34]. Chlorophyll content is positively correlated with photo inhibition, high membrane thermo-stability [35], and water usage [36]. Moreover, chlorophyll content is considered a reliable indicator of WUE and adaptation to drought stress in wheat [36]. Therefore, the development of wheat cultivars that are able to use available water more efficiently and tolerate drought is a major goal 
for increasing wheat productivity under water-limited environments and countries should authorize policies that allocate water to adapt with climate change [10,37-39].

Supplemental irrigation (SI) could allow earlier wheat planting and thus avoidance of terminal heat stress during the grain filling period. Therefore, breeders should select varieties with higher WUE. This system proved to be essential in Jordan, where the variation in rainfall and distribution from year to year results in great fluctuations in production $[14,40]$.

Farmers should avoid drought during the most sensitive stages of growth, mainly the flowering and the grain filling stages, when drought causes poor growth and consequently poor yield. Therefore, SI, if applied in the right amount and at the right time, could make a substantial improvement in the yield potential of wheat [41]. Recently, many studies have shown that proper SI can increase crop yield via improving soil water conditions and the crop WUE. For example, Semcheddine and Hafsi (2014) [42] tested 10 durum wheat cultivars (Triticum durum Desf.) under rain-fed and three irrigation treatments in semi-arid conditions of Eastern Algeria. They reported that irrigation treatments significantly affected grain yield, yield components, and chlorophyll content.

Alternatively, wheat yield can be stabilized by improving crop management to enhance water availability and WUE. Thus, adoption of SI in the rain-fed condition in Jordan should be assessed to cope with the expected water limitation implied by the global climate change and dramatic increase in population. The objectives of the current study were to: investigate the physiological basis controlling yield responses of three spring wheat cultivars in dry areas of Jordan under different water regimes using CTD and SPAD, establish stability levels under fluctuated precipitations and high temperatures as related to the climate change in Jordan by assessing the responses of yield and yield components under different water regimes, and investigate the feasibility of implementing supplemental irrigation of wheat crop in Jordan as a national strategy to cope with global climate change.

\section{Material and Methods}

\subsection{Plant Materials and Cultivar Information}

Two durum wheat (Triticum durum Desf.) cultivars (Cham1 and Acsad65) and one bread wheat (Triticum aestivum L.) cultivar (Ammon) were selected for this experiment (Table 1) based on their reputed differences in yield performance under irrigated and non-irrigated conditions. Cham 1 and Acsad65 were widely used by farmers for its stability, especially in good seasons, whereas Ammon, is a newly released cultivar and still under adoption stage by farmers. These cultivars were not previously assessed using SPAD and CTD. Cham1 is a spring durum wheat variety, erect, low tillering, short, characterized by medium heading, strong pigmentation of coleoptiles and can be distinguished from the other closely related Cham varieties by its very thick parenchyma wall of straw and the sloping shoulder shape of lower glumes. Acsad65 is a spring durum wheat variety, semi-erect, medium tillering, short, suitable for rain-fed agriculture, characterized by early heading and medium maturity, non-pigmented coleoptiles, elevated shoulder of glumes and ovoid grain shape, while Ammon is a spring bread wheat variety, erect, high tillering, tall, medium to late heading, suitable for environmental areas where rainfall is more than $350 \mathrm{~mm}$ [43].

Table 1. Name, pedigree, and year of release of the three wheat cultivars (Triricum aestivum L. and T. durum Defs.) used in this study, adopted from NCARE [44].

\begin{tabular}{ccccc}
\hline Variety Name & Type & Pedigree & Source & Released \\
\hline Cham1 & Durum & 'Waha $=$ plc's'-ruff's'X gta's'-rtte $^{\prime}$ ICARDA $^{1}$ & 1988 \\
Acsad65 & Durum & Stork's'. CM470-1M-2Y-OM//Gdavz-469-AA'S'/STORK'S & CIMMYT $^{2}$ & 1988 \\
Ammon & Bread & Tsi/Vee'S' & ICARDA & 2004 \\
\hline 1 International Center for Agricultural Research in the Dry Areas; ${ }^{2}$ The International Maize and Wheat
\end{tabular}




\subsection{Site Description}

Wheat seeds were sown under field condition at Maru Agricultural Station located in Irbid governorate at $32^{\circ} 33^{\prime} \mathrm{N}$ latitude, $35^{\circ} 51^{\prime} \mathrm{E}$ longitude, and $589 \mathrm{~m}$ above sea level. The experiments were performed from December to June 2013-2014 and 2014-2015 growing seasons. Maru has atypical Mediterranean climate conditions with hot and dry summer and an average annual precipitation of about $380 \mathrm{~mm}$. The soil of experimental field was classified as silty clay with $\mathrm{pH}$ of 7.8 (Table 2).

Table 2. Soil analysis results for the experimental site at Maru experimental station, Jordan.

\begin{tabular}{cc}
\hline Chemical and Physical Properties \\
\hline $\mathrm{P} \%$ & 1.16 \\
$\mathrm{~K} \%$ & 194.0 \\
$\mathrm{CaCO}_{3} \%$ & 1.90 \\
$\mathrm{~N} \%$ & 0.1 \\
$\mathrm{PH}$ & 7.75 \\
E.C ds $/ \mathrm{m}$ & 0.42 \\
Clay & 56.2 \\
Silt & 33.8 \\
Sand & 10.00 \\
\hline
\end{tabular}

\subsection{Cultural Practices and Experimental Design}

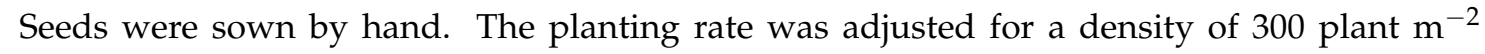
according to the standard practices of the National Center for Agriculture and Extension (NCARE), Jordan. Planting dates were 23 November for 2013-2014 and 6 December for 2014-2015 growing seasons respectively.

Four water supply treatments were applied as a main factor consisting of rain-feds control (T0) and three levels of supplementary irrigations T1, T2 and T3 based on field capacity (FC). The three wheat varieties were split over irrigation treatments as a sub factor in a split plot design with 4 replications. The experiment consisted of $48 \mathrm{sub}$ plots of $20 \mathrm{~m}^{2}$ area (4 replications $\times 4$ water treatments $\times 3$ cultivars). Water was applied using a dripper discharge four litters hour ${ }^{-1}$ when the soil water content dropped below $50 \%$ of the total available water in the upper $90 \mathrm{~cm}$ of the soil depth. A flow meter was used to measure the amount of applied irrigation water. Irrigation was applied at 50\% (T1), $75 \%$ (T2) and $100 \%$ (T3) while the rain-fed treatment (T0) was maintained under no irrigation throughout the growing season.

\subsection{Soil Water Monitoring}

Irrigation decisions were made based on weekly readings of the Time Domain Reflectometer (TDR) (BICO-BT, IMKO 2010, Munich, Germany), which monitors soil moisture content at 15, 30, 45, 60, and $90 \mathrm{~cm}$ soil depth in one replicate. In both years, three access tubes were installed in the central sub plot of each treatment to measure soil water content in $15 \mathrm{~cm}$ increments starting from $15 \mathrm{~cm}$ soil depth down to $90 \mathrm{~cm}$ depth. Field capacity was calculated based on soil depth and root development stage. Actually, root development stage itself reflects a certain period in shoot development. For example, the field capacity was calculated based on soil depth; $15 \mathrm{~cm}$ was corresponding toGS1 to GS25, $30 \mathrm{~cm}$ soil depth corresponds to GS25 to GS30, $45 \mathrm{~cm}$ soil depth corresponds to GS30 to GS59, and $60 \mathrm{~cm}$ soil depth corresponds to GS60 to GS90. In this experiment, nitrogen deficiency was avoided by applying $50 \mathrm{~kg} \mathrm{ha}^{-1}$ of di-ammonium phosphate at sowing and $50 \mathrm{~kg} \mathrm{ha}^{-1}$ Urea $\left(\mathrm{NH}_{2}\right)_{2} \mathrm{CO}(45 \% \mathrm{~N})$ were applied at the tillering stage based on the NCARE-Jordan standard recommendation.

\subsection{Crop Phenology}

Regular observations were made of phonology in terms of thermal time to heading (from emergence to the day when $50 \%$ of plants had spikes) and thermal time to physiological maturity 
(from emergence to the day when all green lamina had senesced, and there was less than $10 \%$ of stem area remaining green). Using a base temperature of development and growth for wheat crop is equal to $5{ }^{\circ} \mathrm{C}[45,46]$. The dates of most important growth stages (flag leaf emergence (GS39), anthesis (GS69) and medium of milk stage (GS75))were observed when $50 \%$ of the plants reached a given developmental stage based on the decimal codes of the growth stages (GS) as revised by Tottman and Broad (1987) [47]. Complete canopy senescence was taken as the date when all green lamina had senesced, and there was less than $10 \%$ of the stem area remaining green. Weather data were daily recorded from the automated weather station at Maru experimental station, less than $0.5 \mathrm{~km}$ from the experimental site. Rainfall $(\mathrm{mm})$ and maximum and minimum air temperatures were recorded from sowing to harvest. Accumulated thermal time was calculated from maximum and minimum daily air temperatures using a base temperature of $5{ }^{\circ} \mathrm{C}$.

\subsection{Canopy Temperature Depression, Chlorophyll Content, Yield Analysis, and Water Use Efficiency}

Canopy temperature was measured per plant based on the decimal code of growth stages (GS) as revised by Tottman and Broad (1987) [47] for all sub-plots at three growth stages (GS39, GS61, and GS75). A hand-held infrared thermometer (Mikron M90 series, Mikron Infrared Instrument Co., Inc., Oakland, NJ, USA) was used to monitor the canopy temperature. The instrument was held to view the crop at an angle of $30^{\circ}$ from the horizontal at right angles to the rows at a distance of $2.0 \mathrm{~m}$ from the sample row and at $50 \mathrm{~cm}$ above the canopy. Readings were made between 13:00 $\mathrm{h}$ and 15:00 $\mathrm{h}$ on sunny days. Each canopy temperature reading was the average of three regarding recorded from different points in each plot. Air temperature and humidity were measured at the same time as canopy temperature to calculate the canopy temperature depression.

Total chlorophyll content (TCC) was determined non-destructively using a portable chlorophyll meter; SPAD 502 Chlorophyll Meter (Spectrum Technologies Inc., Plainfield, IL, USA). Five plants from each irrigation $\times$ genotype combination in four replications were investigated and measured at three stages (GS39, GS61, and GS75) as a leaf chlorophyll index. Readings were taken by clamping the SPAD sensor over the leaf lamina on the first fully expanded flag leaf about halfway between the tip and the base of the leaf. Measurements were not taken over the midrib. A close linear correlation between SPAD values and extractable chlorophyll content has been observed for a wide range of species $[29,42,48]$.

At harvest, shoots from $1 \mathrm{~m}^{2}$ sample area were hand-harvested and counted in two categories: (i) fertile shoots (with spikes) and (ii) infertile shoots (without spikes). For fertile shoots, the spikes were cut off at collar, and the fresh weight of the straw was recorded. The dry weight of the components was recorded after drying for $48 \mathrm{~h}$ at $80^{\circ} \mathrm{C}$. The spikes were counted and then threshed. The grain and chaff were collected, dried at $80^{\circ} \mathrm{C}$ for $48 \mathrm{~h}$ and weighed. A sub-sample of dried grain was taken, cleaned by removing all broken grains by hand, weighed after drying at $80^{\circ} \mathrm{C}$ for $48 \mathrm{~h}$ and the thousand grain weight was calculated. The total dry weight of infertile shoots was recorded. Number of grains spike ${ }^{-1}$ was determined as an average of 10 randomly selected ten spikes plot $^{-1}$. Harvest index was calculated by dividing total grain weight over total plant weight multiplied by 100 .

Gravimetric soil moisture content was measured every two weeks by taking soil samples from different soil depths $(0-15,15-30,30-45,45-60$ and $60-90 \mathrm{~cm})$ and multiplying the value obtained by the average measured bulk density $\left(1.25 \mathrm{gm} \mathrm{cm}^{-3}\right)$ for the experimental site to evaluate the volumetric soil water content. The bulk density was measured by using the core method for different soil depths by digging a soil profile adjacent to the experimental site. The recorded range of bulk density was 1.2 to $1.3 \mathrm{gm} \mathrm{cm}^{-3}$.

The change in the volumetric soil moisture content at planting and harvesting was relatively small so long as the crop root was not accessed below a depth of $60 \mathrm{~cm}$. The WUE was calculated by taken into consideration the rainfall (R) during the growing season (from date of planting until date of maturity) and irrigation quantity (Irr) and the difference in volumetric soil moisture storage (+/-DS) in the soil from the date of planting until the date of harvesting (Equation (1)), whereas deep 
percolation was eliminated from Equation (1) because the amount of rainfall within the two growing seasons (168.2 and $359.6 \mathrm{~mm}$; respectively) is lower than that necessary to cause deep percolation (Dp) and the change in the volumetric soil moisture content in the lower soil depth $(60-90 \mathrm{~cm})$ was constant at pre-planting dates compared with the harvesting date. Most of the rainfall was stored in the root zone of the crop $(0-60 \mathrm{~cm})$ because the crop was planted in a soil with a high water holding capacity and more than $60 \%$ clay (Table 2). Water consumption (WC) was calculated in mm using the following equation $=\mathrm{R}+(+/-\mathrm{DS})+\operatorname{Irr}+\mathrm{Dp}$ (Equation (1)). WUE (WUE) $\left(\mathrm{kg} \mathrm{m}^{-3}\right)$ for grain yield was then calculated by dividing the yield $\left(\mathrm{kg} \mathrm{ha}^{-1}\right)$ by the total water consumption $\left(\mathrm{m}^{3} \mathrm{ha}^{-1}\right)$.

\subsection{Statistical Analysis}

All data were statistically analyzed using Statistical Analysis System STATISTICA 7.0 (Stat Soft Inc., Tulsa, OK, USA). Standard analysis of variance procedures for a split plot design in randomized blocks were used to calculate treatment means, standard errors, and significant differences between treatments. Probability of significance was used to indicate significance among treatments and interactions according to Steel and Torrie [49]. Means were compared using Fisher's protected LSD test at $p \leq 0.05$. The correlation coefficients of agronomic and physiological characteristics were also analyzed.

\section{Results}

In the second season (2014/2015), there was a good amount of precipitation with better distribution compared to the first season (2013/2014), which implies that the 2014/2015 season was wet since the precipitation quantity and uniform distribution kept field capacity at optimum level and only small amounts of irrigation water were supplied before heading (GS45) and at medium milk stage (GS75). While in 2013/2014 season the three levels of supplemental irrigation were applied along the whole season (Figure 1). For this particular reason the analysis of variance during statistical analysis was presented without cross-year analysis.

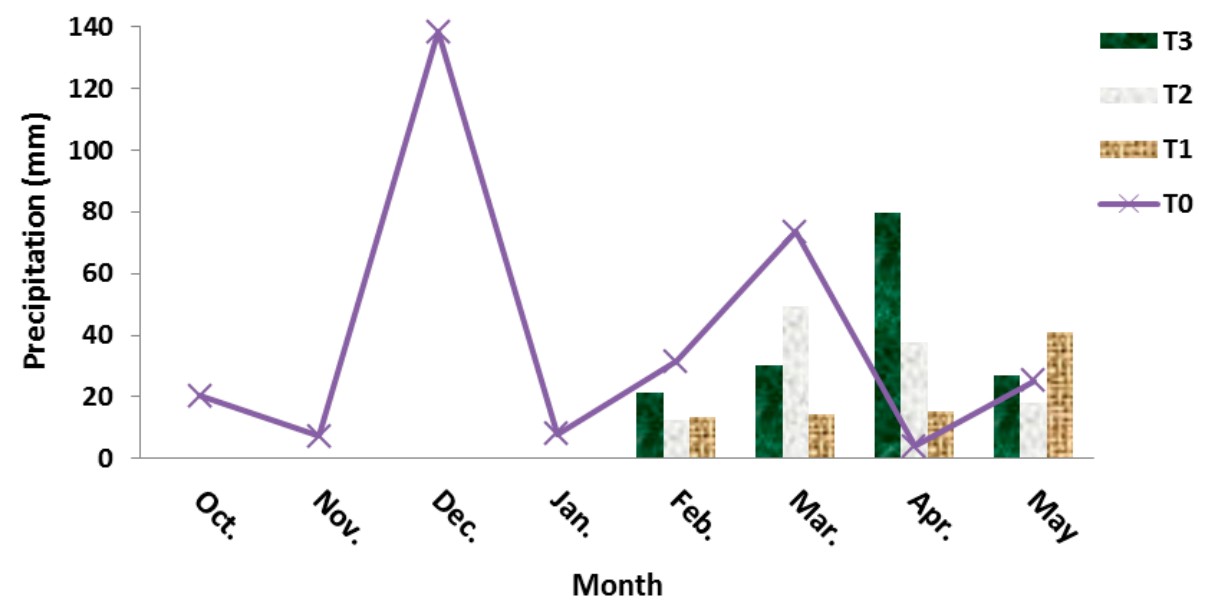

Figure 1. Monthly precipitation and irrigation amount (mm) (T0: rain-fed; T1 50\%; T2 75\%; T3 100\% of field capacity) at Maru station (Jordan) during the 2014 growing season.

\subsection{Climatic Conditions}

The total annual precipitation in the 2013-2014 and 2014-2015 seasons was $307.6 \mathrm{~mm}$ and $509.6 \mathrm{~mm}$, respectively, compared to the historical annual average of $380 \mathrm{~mm}$. However, the rainfall pattern demonstrated monthly inconsistency (Figures 1 and 2). The first season was characterized by lower precipitation (less than $81 \%$ of the long-term average) and unfavorable distribution. Therefore, SI treatments were applied four times from February to May (Figure 1). On the other hand, 
the precipitation was greater than the long-term average by $27.4 \%$ in the second season. Such a high precipitation level eliminated the drought stress effect on the crop in the unirrigated treatments.

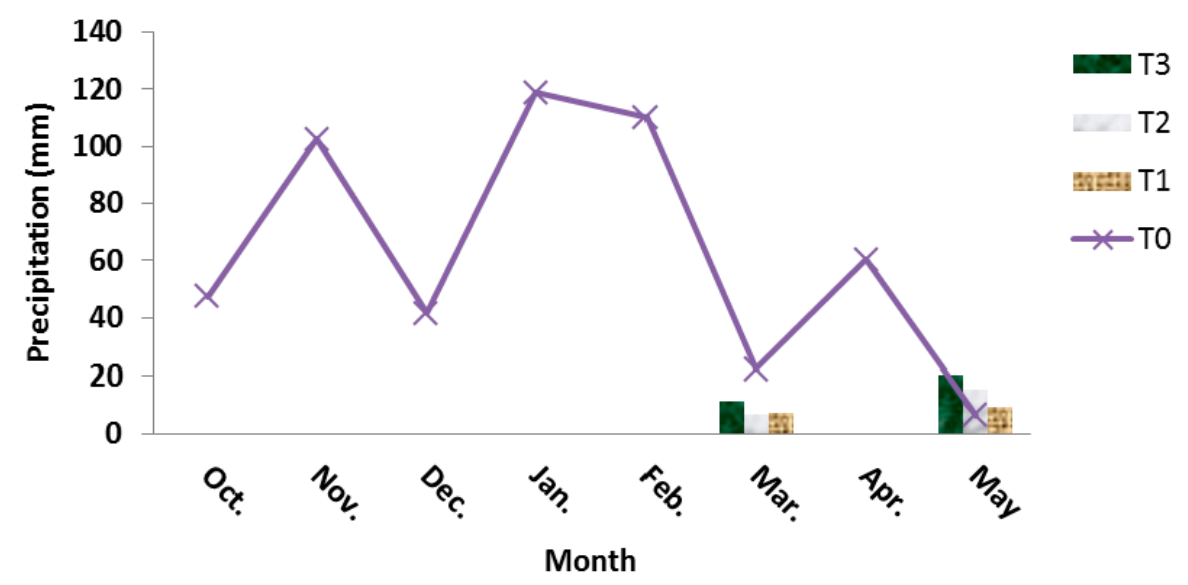

Figure 2. Monthly precipitation and irrigation amount (mm) (T0: rain-fed; T1 50\%; T2 75\%; T3 100\% of field capacity) at Maru station (Jordan) during the 2015 growing season.

When calculated over the whole year, an average air temperature was warmer in 2013-2014 compared to the second season until December but cooler from January until the end of the season. In general, the second season was cooler than the first season (Figure 3).

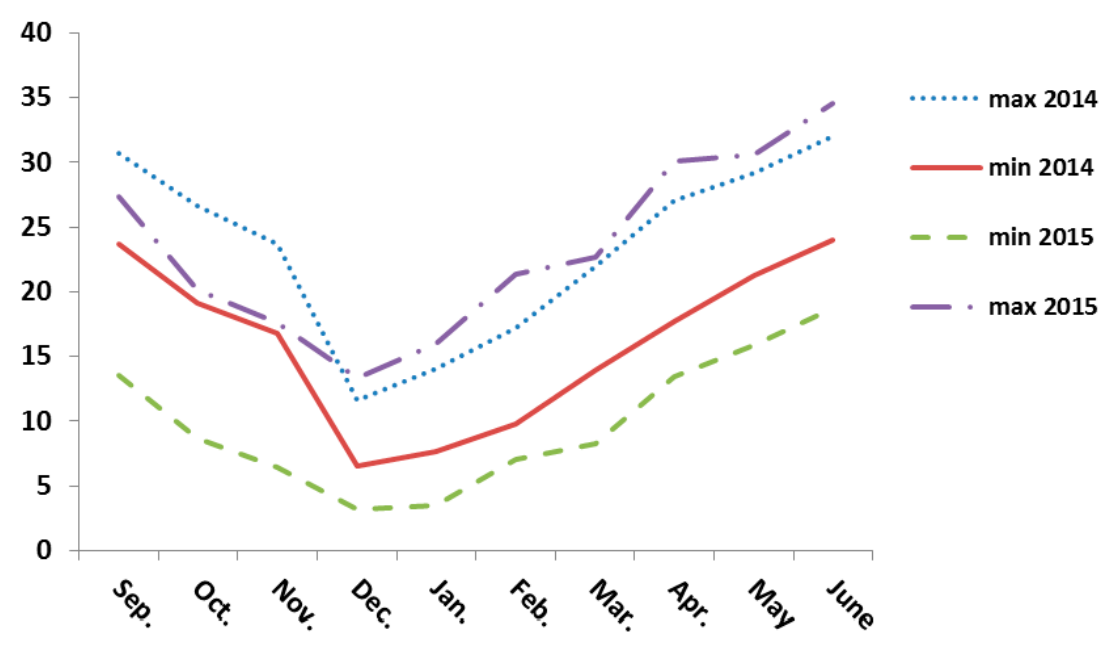

Figure 3. Maximum and minimum monthly temperatures $\left({ }^{\circ} \mathrm{C}\right)$ in Maru station during two growing seasons, 2014 and 2015.

\subsection{Analysis of Variance}

The growing seasons are referred to hereafter by their harvest years, 2014 and 2015 (i.e., 2013-2014 is referred to as 2014). 
Table 3. Some important agronomic characteristics measured for three wheat cultivars (Triricum aestivum L. and T. durum Defs.) grown under four water regimes during the 2014 and 2015 growing seasons. Means within each column followed by the same letter(s) are not significantly different at $p \leq 0.05$ according to LSD ${ }^{1}$.

\begin{tabular}{|c|c|c|c|c|c|c|c|c|c|c|}
\hline \multirow[b]{2}{*}{$\begin{array}{c}\text { Water } \\
\text { Regime }\end{array}$} & \multicolumn{5}{|c|}{2014 Growing Season } & \multicolumn{5}{|c|}{2015 Growing Season } \\
\hline & $\begin{array}{l}\text { Number of } \\
{\text { Spikes } m^{-2}}^{-2}\end{array}$ & $\begin{array}{l}\text { Number of } \\
\text { Grains } \\
\text { spike }^{-1}\end{array}$ & $\begin{array}{l}1000 \text { Grain } \\
\text { Weight (g) }\end{array}$ & $\begin{array}{l}\text { Thermal Time } \\
\text { to Heading } \\
\left(\text { GDD }^{2}\right)\end{array}$ & $\begin{array}{l}\text { Thermal Time to } \\
\text { Physiological } \\
\text { Maturity (GDD) }\end{array}$ & $\begin{array}{l}\text { Number of } \\
{\text { Spikes } m^{-2}}^{-2}\end{array}$ & $\begin{array}{c}\text { Number of } \\
\text { Grains spike }^{-1}\end{array}$ & $\begin{array}{l}1000 \text { Grain } \\
\text { Weight (g) }\end{array}$ & $\begin{array}{l}\text { Thermal Time } \\
\text { to Heading } \\
\text { (GDD) }\end{array}$ & $\begin{array}{l}\text { Thermal Time to } \\
\text { Physiological } \\
\text { Maturity (GDD) }\end{array}$ \\
\hline T0 & $188^{\mathrm{d}}$ & $34.68^{c}$ & $33.97^{c}$ & $680^{b}$ & $1070^{a}$ & $269^{b}$ & $38.46^{\mathrm{ab}}$ & $37.95^{\mathrm{ab}}$ & $766^{c}$ & $1241^{a}$ \\
\hline $\mathrm{T} 1$ & $251^{c}$ & $40.07^{\mathrm{b}}$ & $37.62^{b}$ & $719^{a}$ & $1121^{a}$ & $291^{a b}$ & $38.25^{\mathrm{ab}}$ & $37.48^{b}$ & $774^{\mathrm{b}}$ & $1261^{b}$ \\
\hline $\mathrm{T} 2$ & $267^{b}$ & $39.98^{b}$ & $38.47^{b}$ & $718^{a}$ & $1119^{a}$ & $306^{\mathrm{a}}$ & $37.33^{\mathrm{b}}$ & $38.34^{a b}$ & $773^{b}$ & $1256^{\mathrm{b}}$ \\
\hline T3 & $283^{a}$ & $40.77^{\mathrm{a}}$ & $42.18^{a}$ & $720^{a}$ & $1157^{\mathrm{a}}$ & $287^{a b}$ & $38.78^{a}$ & $39.00^{a}$ & $805^{a}$ & $1297^{c}$ \\
\hline LSD & 8.61 & 0.67 & 2.53 & 13.5 & 62.8 & 23.70 & 1.44 & 1.21 & 6.5 & 11.05 \\
\hline \multicolumn{11}{|l|}{ Variety } \\
\hline Cham1 & $250^{a}$ & $38.98^{b}$ & $37.16^{\mathrm{b}}$ & $713^{a}$ & $1160^{a}$ & $292^{a}$ & $37.45^{b}$ & $37.56^{\mathrm{b}}$ & $792^{a}$ & $1275^{a}$ \\
\hline Acsad65 & $230^{b}$ & $34.65^{c}$ & $41.10^{\mathrm{a}}$ & $699^{b}$ & $1099^{a}$ & $276^{\mathrm{b}}$ & $35.62^{b}$ & $41.95^{\mathrm{a}}$ & $755^{b}$ & $1274^{\mathrm{a}}$ \\
\hline Ammon & $263^{a}$ & $42.99^{\text {a }}$ & $35.91^{b}$ & $716^{a}$ & $1090^{\mathrm{a}}$ & $298^{\mathrm{a}}$ & $41.54^{\mathrm{a}}$ & $35.07^{c}$ & $792^{\mathrm{a}}$ & $1243^{b}$ \\
\hline Mean & 247 & 38.87 & 38.06 & 709 & 1116 & 288 & 38.20 & 38.19 & 779 & 1264 \\
\hline LSD & 14.81 & 1.19 & 1.54 & 8.73 & 82.05 & 15.00 & 2.19 & 1.22 & 6.45 & 9.49 \\
\hline
\end{tabular}

Table 4. Grain yield ( $\mathrm{t} \mathrm{ha}^{-1}$ ), above-ground biomass ( $\mathrm{t} \mathrm{ha} \mathrm{a}^{-1}$ ), harvest index (HI), and water use efficiency (WUE) for three wheat cultivars (Triricum aestivum L. and T. durum Defs.) grown under four water regimes during the 2014 and 2015 growing seasons. Means within each column followed by the same letter(s) are not significantly different at $p \leq 0.05$ according to LSD.

\begin{tabular}{|c|c|c|c|c|c|c|c|c|c|c|}
\hline \multirow[b]{2}{*}{$\begin{array}{c}\text { Water } \\
\text { Regime }\end{array}$} & \multicolumn{5}{|c|}{2014 Growing Season } & \multicolumn{5}{|c|}{2015 Growing Season } \\
\hline & $\begin{array}{l}\text { Grain Yield } \\
\left(\mathrm{tha}^{-1}\right)\end{array}$ & $\begin{array}{l}\text { Above-Ground } \\
\text { Biomass } \\
\left(\mathrm{t} \mathrm{ha}^{-1}\right)\end{array}$ & $\begin{array}{l}\text { Harvest } \\
\text { Index (HI) }\end{array}$ & $\begin{array}{l}\text { WUE of Grain } \\
\text { Yield }\left(\mathrm{kg} \mathrm{m}^{-3}\right)\end{array}$ & $\begin{array}{c}\text { WUE for } \\
\text { above-Ground } \\
\text { Biomass }\left(\mathrm{kg} \mathrm{m}^{-3} \text { ) }\right.\end{array}$ & $\begin{array}{l}\text { Grain Yield } \\
\left(\mathrm{t} \mathrm{ha}^{-1}\right)\end{array}$ & $\begin{array}{l}\text { Above-Ground } \\
\text { Biomass }\left(\mathrm{t} \mathrm{ha}^{-1}\right)\end{array}$ & $\begin{array}{l}\text { Harvest } \\
\text { Index (HI) }\end{array}$ & $\begin{array}{l}\text { WUE of Grain } \\
\text { Yield }\left(\mathrm{kg} \mathrm{m}^{-3}\right)\end{array}$ & $\begin{array}{c}\text { WUE for } \\
\text { above-Ground } \\
\text { Biomass }\left(\mathrm{kg} \mathrm{m}^{-3} \text { ) }\right.\end{array}$ \\
\hline T0 & $2.24^{\mathrm{d}}$ & $9.1^{\mathrm{c}}$ & $0.249^{\mathrm{d}}$ & $0.82^{c}$ & $3.31^{\mathrm{a}}$ & $3.89^{\mathrm{b}}$ & $10.9^{\mathrm{c}}$ & $0.356^{\mathrm{b}}$ & $0.97^{\mathrm{a}}$ & $2.51^{\mathrm{b}}$ \\
\hline $\mathrm{T} 1$ & $3.81^{\mathrm{c}}$ & $12.3^{\mathrm{b}}$ & $0.308^{c}$ & $1.07^{b}$ & $3.47^{\mathrm{a}}$ & $4.17^{\mathrm{a}}$ & $11.6^{\mathrm{ab}}$ & $0.360^{\mathrm{b}}$ & $0.95^{\mathrm{ab}}$ & $2.63^{\mathrm{a}}$ \\
\hline $\mathrm{T} 2$ & $4.10^{\mathrm{b}}$ & $11.6^{\mathrm{b}}$ & $0.350^{\mathrm{a}}$ & $1.07^{\mathrm{b}}$ & $3.03^{b}$ & $4.32^{\mathrm{a}}$ & $11.8^{\mathrm{a}}$ & $0.365^{\mathrm{b}}$ & $0.97^{\text {a }}$ & $2.66^{\mathrm{a}}$ \\
\hline T3 & $4.79^{\mathrm{a}}$ & $14.2^{\mathrm{a}}$ & $0.338^{\mathrm{b}}$ & $1.13^{\mathrm{a}}$ & $3.35^{\text {a }}$ & $4.28^{\text {a }}$ & $11.3^{\mathrm{bc}}$ & $0.377^{a}$ & 0.93 ab & $2.47^{\mathrm{b}}$ \\
\hline LSD & 0.22 & 0.90 & 0.012 & 0.06 & 0.246 & 0.25 & 0.47 & 0.011 & 0.06 & 0.107 \\
\hline \multicolumn{11}{|l|}{ Variety } \\
\hline Cham1 & $3.74^{\mathrm{b}}$ & $12.1^{\mathrm{a}}$ & $0.302^{b}$ & $1.02^{\mathrm{b}}$ & $3.40^{\mathrm{a}}$ & $4.24^{\mathrm{a}}$ & $11.6^{\mathrm{a}}$ & $0.364^{\mathrm{ab}}$ & $0.95^{\mathrm{a}}$ & $2.62^{\mathrm{a}}$ \\
\hline Acsad65 & $3.33^{\mathrm{b}}$ & $11.1^{\mathrm{b}}$ & $0.294^{c}$ & $0.91^{c}$ & $3.10^{\mathrm{b}}$ & $3.92^{b}$ & $10.9^{\mathrm{b}}$ & $0.360^{\mathrm{b}}$ & $0.88^{\mathrm{b}}$ & $2.45^{b}$ \\
\hline Ammon & $4.15^{\mathrm{a}}$ & $12.1^{\mathrm{b}}$ & $0.337^{\mathrm{a}}$ & $1.14^{\mathrm{a}}$ & 3.37 a & $4.34^{\mathrm{a}}$ & $11.7^{\text {a }}$ & $0.371^{\mathrm{a}}$ & $0.95^{\mathrm{a}}$ & $2.63^{\mathrm{a}}$ \\
\hline Mean & 3.74 & 11.8 & 0.311 & 1.02 & 3.29 & 4.17 & 11.4 & 0.365 & 0.94 & 2.566 \\
\hline LSD & 0.23 & 0.68 & 0.006 & 0.07 & 0.187 & 0.17 & 0.42 & 0.008 & 0.05 & 0.095 \\
\hline
\end{tabular}


Table 5. Total chlorophyll content (TCC), measured by SPAD, and Canopy Temperature Depression (CTD) for three wheat cultivars (Triricum aestivum L. and T. durum Defs.) grown under four water regimes during the 2014 and 2015 growing seasons. Means within each column followed by the same letter(s) are not significantly different at $p \leq 0.05$ according to LSD.

\begin{tabular}{|c|c|c|c|c|c|c|c|c|c|c|c|c|}
\hline \multirow{3}{*}{ Water Regime } & \multicolumn{6}{|c|}{2014 Growing Season } & \multicolumn{6}{|c|}{2015 Growing Season } \\
\hline & \multicolumn{3}{|c|}{ SPAD } & \multicolumn{3}{|c|}{ CTD } & \multicolumn{3}{|c|}{ SPAD } & \multicolumn{3}{|c|}{ CTD } \\
\hline & GS39 & GS69 & GS75 & GS39 & GS69 & GS75 & GS39 & GS69 & GS75 & GS39 & GS69 & GS75 \\
\hline T0 & $48^{\mathrm{b}}$ & $50^{b}$ & $44^{c}$ & $1.31^{\mathrm{c}}$ & $3.37^{\mathrm{c}}$ & $2.62^{c}$ & $53^{a b}$ & $52^{a}$ & $49^{b}$ & $4.67^{\mathrm{b}}$ & $7.45^{c}$ & $3.29^{b}$ \\
\hline $\mathrm{T} 1$ & $49^{a}$ & $52^{\mathrm{ab}}$ & $45^{\mathrm{bc}}$ & $2.57^{b}$ & $3.78^{\mathrm{b}}$ & $4.45^{\mathrm{b}}$ & $53^{\mathrm{ab}}$ & $52^{a}$ & $49^{b}$ & $5.15^{\mathrm{b}}$ & $7.86^{\mathrm{b}}$ & $3.52^{b}$ \\
\hline $\mathrm{T} 2$ & $50^{a b}$ & $53^{a}$ & $47^{\mathrm{ab}}$ & $3.72^{\mathrm{a}}$ & $4.19^{\mathrm{a}}$ & $4.75^{\mathrm{ab}}$ & $52^{b}$ & $52^{a}$ & $48^{b}$ & $5.69^{a}$ & $7.45^{c}$ & $3.55^{b}$ \\
\hline T3 & $50 \mathrm{a}$ & $53^{\mathrm{a}}$ & $48^{\mathrm{a}}$ & $3.31^{\mathrm{a}}$ & $4.27^{\mathrm{a}}$ & $5.20^{\mathrm{a}}$ & $53^{\mathrm{a}}$ & $54^{\mathrm{a}}$ & $52^{\mathrm{a}}$ & $5.70^{\mathrm{a}}$ & $8.74^{\mathrm{a}}$ & $4.09^{\mathrm{a}}$ \\
\hline LSD & 1.5 & 1.8 & 1.4 & 0.58 & 0.36 & 0.55 & 0.8 & 2.0 & 1.2 & 0.50 & 0.32 & 0.37 \\
\hline \multicolumn{13}{|l|}{ Variety } \\
\hline Cham1 & $49^{a}$ & $52^{a}$ & $46^{b}$ & $2.71^{\mathrm{ab}}$ & $4.02^{\mathrm{a}}$ & $4.16^{b}$ & $53^{a}$ & $52^{a}$ & $49^{b}$ & $5.26^{b}$ & $8.22^{\mathrm{a}}$ & $3.53^{b}$ \\
\hline Acsad65 & $49^{a}$ & $52^{\mathrm{a}}$ & $44^{\mathrm{c}}$ & $2.51^{b}$ & $3.72^{b}$ & $3.51^{\mathrm{c}}$ & $53^{a}$ & $53^{a}$ & $48^{b}$ & $4.92^{b}$ & $7.35^{b}$ & $3.02^{c}$ \\
\hline Ammon & $49^{\mathrm{a}}$ & $52^{a}$ & $48^{a}$ & $2.95^{\mathrm{a}}$ & $3.97 \mathrm{ab}$ & $5.09^{a}$ & $53^{a}$ & $53^{a}$ & $51^{\mathrm{a}}$ & $5.74^{\mathrm{a}}$ & $8.11^{\mathrm{a}}$ & $4.29^{\mathrm{a}}$ \\
\hline Mean & 49 & 52 & 46 & 2.72 & 3.9 & 4.25 & 53 & 53 & 49 & 5.30 & 7.89 & 3.61 \\
\hline LSD & 1.1 & 1.1 & 1.2 & 0.04 & 0.29 & 3.94 & 1.5 & 0.7 & 1.4 & 0.39 & 0.39 & 0.30 \\
\hline
\end{tabular}


In the 2014 growing season, combined analysis of variance showed significant genotypic differences $(p<0.05)$ for all morpho-physiological traits examined except for thermal time to maturity and total chlorophyll content (TCC) at pre-anthesis and anthesis stages. Significant differences were also observed between four SI treatments applied on the three wheat cultivars for all traits studied except for thermal time to maturity and TCC at anthesis (Tables 3-5). The interaction between irrigation treatments and wheat cultivars was only significant for grains spike ${ }^{-1}$, harvest index, TCC, and CTD post-anthesis. On the other hand, the results of the 2015 growing season showed genotypic differences for all measured traits except for harvest index (HI) and TCC the pre-anthesis and anthesis stages. Significant differences were observed, as well, between the four SI treatments applied on the wheat cultivars tested for all measured traits except for biological yield, grains spike ${ }^{-1}$, thousand grain weight (TGW), TCC pre-anthesis and at anthesis, and WUE (Tables 3-5). Furthermore, the interaction between irrigation treatments and cultivars was not significant $(p>0.05)$ for all measured traits except for spikes $\mathrm{m}^{-2}$, grains spike ${ }^{-1}$, TGW, thermal time to maturity, and CTD at anthesis and post-anthesis.

\subsection{Selected Agronomic Characteristics and Yield Components}

SI increased spikes $\mathrm{m}^{-2}$ in both years (Table 3). In 2014, all treatments of SI differed significantly from each other. Spikes $\mathrm{m}^{-2}$ varied from 188 (T0) to 283 (T3), whereas all the three levels of SI produced the same effect in 2015 except for T2. Cultivars significantly differed in spikes $\mathrm{m}^{-2}$ and grains spike ${ }^{-1}$ in both seasons where Ammon was the highest and Acsad65 was the lowest (Table 3).

In 2014, SI increased grains spike ${ }^{-1}$ compared to the rain-fed conditions (Table 3). T3 produced more grains than the other SI treatments. On the other hand, there were no significant differences between SI treatments and the rain-fed conditions in 2015.

In 2014, TGW increased from $33.16 \mathrm{~g}$ under rain-fed conditions (T0) to $42.18 \mathrm{~g}$ under $100 \%$ FC (T3), whereas no significant differences between SI and the rain-fed conditions in TGW were observed in 2015 (Table 3). Genotypic differences in TGW were found among the three cultivars tested in both seasons, where Acsad65 produced the highest TGW and Ammon produced the lowest TGW (Table 3).

\subsection{Thermal Time to Heading and Physiological Maturity (Base Temperature $=5{ }^{\circ} \mathrm{C}$ )}

SI increased thermal time to heading in both seasons (Table 3). Genotypic differences in thermal time to heading were found among the three cultivars in both years, withCham 1 and Ammon needing longer thermal time to reach heading compared to Acsad65 (Table 3).

On the other hand, SI has resulted in significant differences in thermal time to physiological maturity only in 2015 (Table 3). Similar trend was observed regarding genotypic differences, where significant variations were only observed in 2015.

\subsection{Grain Yield, Above-Ground Biomass (AGBM), and Harvest Index (HI)}

In both seasons, significant differences were observed in SI and cultivars for grain yield, AGBM and HI (Table 4). Cultivars that were not irrigated (T0) yielded $2.24 \mathrm{t} \mathrm{ha}^{-1}, 3.89 \mathrm{t} \mathrm{ha}^{-1}$ compared to $4.79 \mathrm{t} \mathrm{ha}^{-1}$ and $4.28 \mathrm{tha}^{-1}$ for cultivars provided with SI (T3) under $100 \%$ of FC in 2014 and 2015; respectively (Table 4).

In both seasons, Ammon produced the highest yield andAcsad65 produced the lowest (Table 4).

SI significantly increased the AGBM in both seasons (Table 4). In 2014, AGBM increased from $9.1 \mathrm{t} \mathrm{ha}^{-1}$ under rain-fed conditions up to $14.2 \mathrm{t} \mathrm{ha}^{-1}$ under $100 \%$ FC. Similarly, in 2015 SI increased AGBM at T1 (6\%) and T2 (8\%) compared to T0 (Table 4).

Cultivars significantly differed in AGBM in both seasons (Table 4), with Cham1 producing the highest AGBM value and Acsad65 the lowest (Table 4).

SI increased HI in both seasons (Table 4). In 2014, the highest value of HI (0.35) was reached at T2, whereas T0 showed the lowest HI (0.25). In 2015, T3 had the highest HI (0.38) compared to T0, $\mathrm{T} 1$, and $\mathrm{T} 2$, which were non-significantly different from each other. Similarly, cultivars were found to 
differ significantly in their HI in both seasons (Table 4). In both seasons, Ammon had the highest HI value whereas Acsad65 had the lowest.

\subsection{Water Use Efficiency (WUE) $\left(\mathrm{kg} \mathrm{m}^{-3}\right)$}

In general, SI increased WUE for grain yield and AGBM in both seasons (Table 4). All levels of supplemental irrigation used in this study resulted in higher grain yield compared to the rain-fed conditions (T0). Genotypic differences were observed in both seasons. Again, Ammon has the highest WUE of grain yield among the different cultivars tested, whereas Acsad65 has the lowest.

No significant differences were found in WUE for the AGBM in 2014 (Table 4) between rain-fed treatment (T0) and supplemental irrigation at 50\% and 100\% FC (T1 and T3, respectively). In 2015, the lowest WUE values for AGBM were obtained for 100\% FC (T3) and rain-fed treatment (T0) compared to 50\% and 75\% FC treatment (T1 and T2, respectively). In 2014 and 2015, WUE for AGBM showed significant genotypic variation in which Cham1 and Ammon had greater values than Acsad65.

\subsection{Total Chlorophyll Content (TCC)}

Results indicated that SI significantly affected TCC in 2014 (Table 5). The availability of water was found to increase the TCC mainly during post-anthesis period. The highest TCC was reported for T3 followed by T2. In 2015, only T3 was significantly different from T0 at GS75. In both seasons, genotypic differences in TCC were only evident during post-anthesis (GS75), where Ammon had the highest TCC values and Acsad65 had the lowest values.

\subsection{Canopy Temperature Depression (CTD)}

In both seasons, SI increased CTD values in both seasons and at all growth stages tested (Table 5). CTD values were increased upon crop growth and development (Table 5).

Significant genotypic differences were observed among all cultivars in both seasons. In addition, concerning all growth stages experimented in 2014 and 2015, Ammon significantly exceeded all other cultivars, with Acsad65 having the lowest CTD (Table 5).

\subsection{Correlation among Characteristics}

The correlations among characteristics across both seasons over the four water regimes were presented in Table 6, Figures 4 and 5. Grain yield was positively correlated with all measured traits except for WUE of AGBM. TCC measured at GS39 was highly correlated with grain yield, HI, spikes $\mathrm{m}^{-2}$ and grains spike ${ }^{-1}$. TCC at GS69 was also strongly correlated with spike $\mathrm{m}^{-2}$ and TGW. TCC at GS39, GS69 and GS75 were positively correlated with thermal time to heading and thermal time to physiological maturity. TCC at GS75 was correlated with WUE for grain yield, while there was a neutral effect at GS39 and GS69. Furthermore, CTD was positively correlated with grain yield. CTD measured at GS39 was positively correlated with all characteristics except for grains spike ${ }^{-1}$ and TGW, while CTD measured at GS69 was also correlated with all characteristics studied except for grains spike ${ }^{-1}$, TGW, and AGBM. CTD measured at GS75 was highly correlated with AGBM, grain yield, spike $\mathrm{m}^{-2}$, and grains spike ${ }^{-1}$. The CTD measured at post-anthesis was highly correlated with WUE of grain yield. 
Table 6. Correlation coefficients for 16 characteristics of three wheat varieties grown under four water regimes during two seasons.

\begin{tabular}{|c|c|c|c|c|c|c|c|c|c|c|c|c|c|c|c|c|}
\hline Variable & TTH & TTM & PLH & AGBM & GYLD & HI & SPM & GNPS & TGW & SPAD39 & SPAD69 & SPAD75 & CTD39 & CTD69 & CTD75 & WUEOGBM \\
\hline \multicolumn{17}{|l|}{ TTH } \\
\hline TTM & 0.68 ** & & & & & & & & & & & & & & & \\
\hline PLH & 0.68 ** & $0.64 * *$ & & & & & & & & & & & & & & \\
\hline AGBM & $0.36 * *$ & $0.24 *$ & $0.23 *$ & & & & & & & & & & & & & \\
\hline GYLD & $0.56^{* *}$ & $0.37 * *$ & 0.50 ** & $0.69^{* *}$ & & & & & & & & & & & & \\
\hline $\mathrm{HI}$ & $0.79 * *$ & $0.55 * *$ & $0.67^{* *}$ & $0.39 * *$ & $0.79 * *$ & & & & & & & & & & & \\
\hline SPM & 0.64 ** & $0.47^{* *}$ & 0.62 ** & $0.50^{* *}$ & $0.82 * *$ & $0.75^{* *}$ & & & & & & & & & & \\
\hline GNPS & 0.21 * & -0.01 & -0.06 & $0.40^{* *}$ & 0.55 ** & $0.40^{* *}$ & $0.23 *$ & & & & & & & & & \\
\hline TGW & -0.01 & 0.15 & $0.39^{* *}$ & 0.18 & $0.26^{*}$ & 0.19 & 0.06 & -0.23 * & & & & & & & & \\
\hline SPAD39 & $0.75^{* *}$ & $0.64 * *$ & $0.70 * *$ & 0.15 & $0.40 * *$ & $0.66^{* *}$ & $0.54^{* *}$ & 0.01 & 0.14 & & & & & & & \\
\hline SPAD69 & $0.38 * *$ & $0.31 * *$ & $0.36^{* *}$ & $0.34^{* *}$ & $0.37 * *$ & $0.40 * *$ & $0.35^{* *}$ & 0.08 & $0.27 * *$ & $0.38^{* *}$ & & & & & & \\
\hline SPAD75 & 0.68 ** & $0.49 * *$ & $0.48^{* *}$ & $0.38 * *$ & $0.55^{* *}$ & $0.67^{* *}$ & 0.51 ** & $0.36^{* *}$ & 0.00 & 0.57 ** & $0.35 * *$ & & & & & \\
\hline CTD39 & 0.87 ** & $0.68 * *$ & $0.76^{* *}$ & $0.33^{* *}$ & $0.62 * *$ & $0.83 * *$ & $0.72 * *$ & 0.18 & 0.09 & $0.72 * *$ & 0.38 ** & $0.66 * *$ & & & & \\
\hline CTD69 & $0.90 * *$ & $0.73 * *$ & $0.75^{* *}$ & 0.18 & $0.41^{* *}$ & $0.70^{* *}$ & $0.56^{* *}$ & 0.07 & 0.02 & 0.78 & $0.26 * *$ & $0.62 * *$ & $0.87^{* *}$ & & & \\
\hline CTD75 & 0.11 & -0.12 & -0.03 & $0.63 * *$ & $0.69^{* *}$ & $0.37^{* *}$ & $0.39 * *$ & $0.67^{* * *}$ & 0.02 & -0.06 & 0.15 & $0.34 * *$ & 0.12 & $-0.11 * *$ & & \\
\hline WUEAGBM & $0.62-* *$ & $-0.55^{* *}$ & $-0.63 * *$ & $0.21 * *$ & -0.03 & $-0.56^{* *}$ & $-0.22 * *$ & $0.23 *$ & -0.17 & $-0.68^{* *}$ & $-0.22 * *$ & $-0.38^{* *}$ & $-0.64^{* *}$ & $-0.73 * *$ & $0.40^{* *}$ & \\
\hline WUEGYLD & 0.06 & -0.11 & -0.04 & $0.60 * *$ & $0.77^{* *}$ & $0.36^{* *}$ & $0.50 * *$ & $0.66^{* *}$ & 0.02 & -0.12 & 0.15 & $0.22 *$ & 0.09 & -0.16 & $0.83^{* *}$ & $0.55^{* *}$ \\
\hline
\end{tabular}

$* *, *$ are significant at $p \leq 0.01$ and $p \leq 0.05$, respectively. TTH (thermal time to heading), TTM (thermal time to maturity), PLH (plant height), AGBM (above-ground biomass), GYLD (grain yield), HI (harvest index), SPM spikes per meter square), GNPS (grains per spike), TGW (thousand grain weight), SPAD39 (total chlorophyll content at stage 39), SPAD69(total chlorophyll content at stage 69), SPAD75 (total chlorophyll content at stage 75), CTD39 (canopy temperature depression at stage 39), CTD69 (canopy temperature depression at stage 69), CTD75 (canopy temperature depression at stage 75), WUEAGBM (water use efficiency of above- ground biomass), WUEGYLD (water use efficiency of grain yield). 

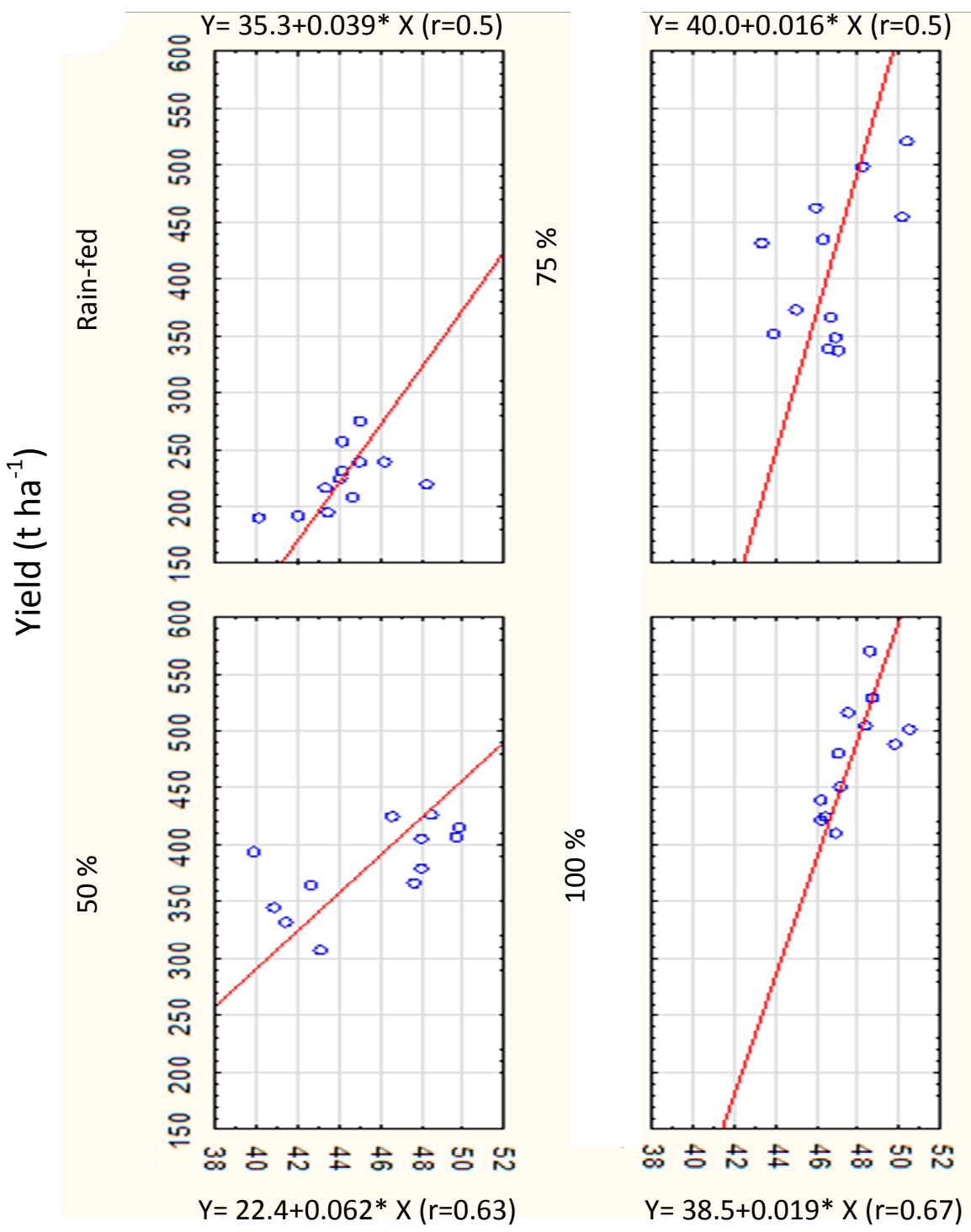

\section{SPAD at GS 75}

Figure 4. Relationship between grain yield and SPAD at GS75 (medium milk stage) of three wheat cultivars (Triricum aestivum L. and T. durum Defs.) grown in Jordan under the corresponding four water regimes. 


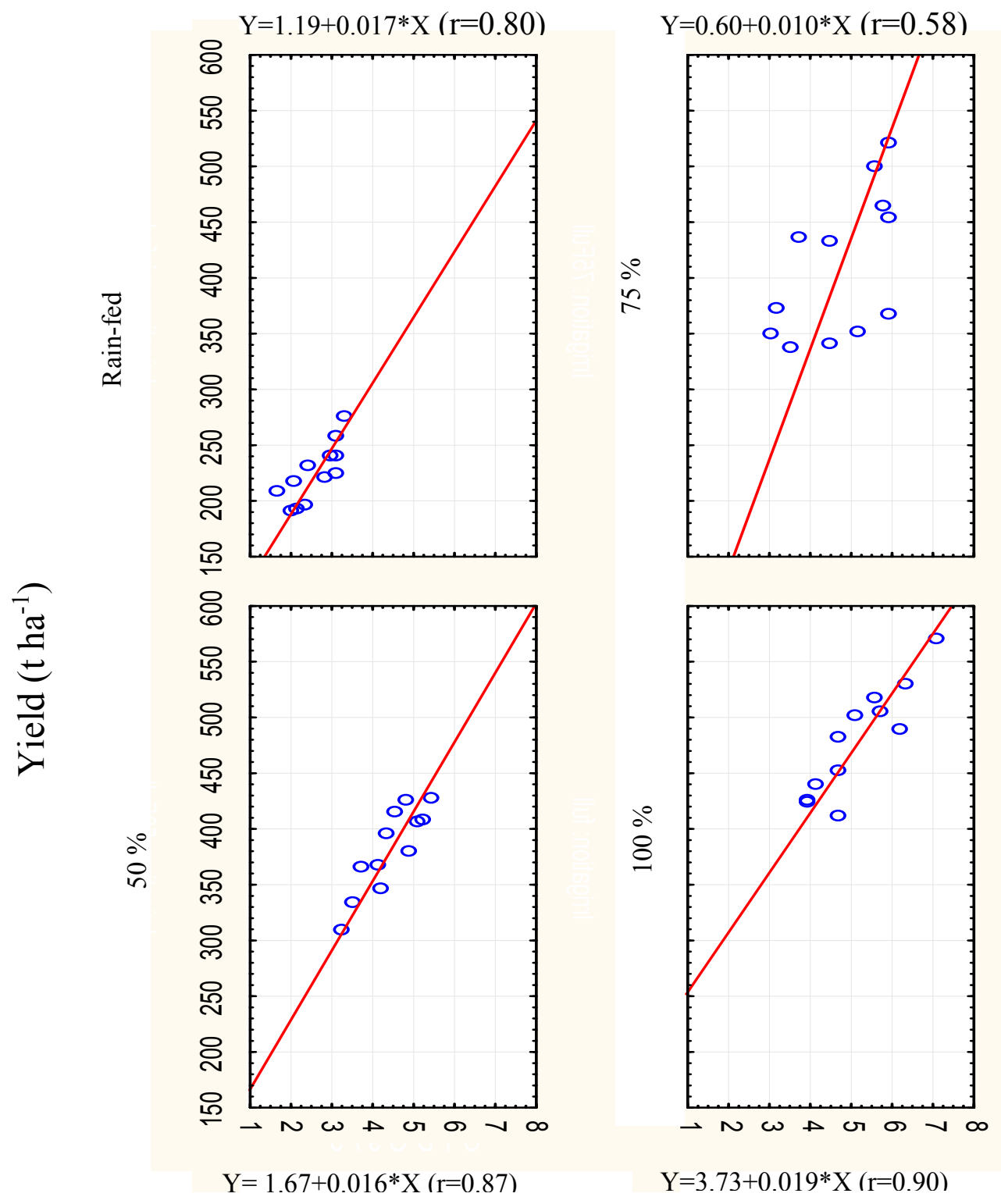

CTD at GS 75

Figure 5. Relationship between grain yield and CTD at GS75 (medium milk stage) of three wheat (Triricum aestivum L. and T. durum Defs.) cultivars grown in Jordan under the corresponding four water regimes. 


\section{Discussion}

\subsection{Climatic Conditions}

In Jordan, water deficit is the most limiting factor for wheat yield in most years [13]. The unfavorable distribution of rain over the growing season and the year-to-year fluctuations constitute a major constraint to wheat growth and yield [50-54]. Drought typically occurs late in the season, with onset of stress largely synchronized with flowering. Stable varieties and SI are needed in such situations in Jordan as a strategic choice followed by farmers to stabilize wheat yields, especially under terminal drought stress conditions [55-57]. SI is a common practice in dry regions with the aim of improving crop yield by adding small amounts of water to rain-fed crops during the times when rainfall fails to provide sufficient moisture for normal plant growth and development [58,59], and meet the need for food security all over the world.

In the current study, the two seasons in which this study was conducted were considered good examples of precipitation fluctuations and bad distribution of rainfall. Annual precipitation in the two seasons was 307 and $509 \mathrm{~mm}$, respectively, compared to the long-term average mean of $380 \mathrm{~mm}$. However, the rainfall prototype illustrated monthly variability between the two growing seasons. The precipitation in the first season was less than $81 \%$ of the long-term mean, which represented an example of dry seasons. Hence, applying SI was done over four months and matched tillering, booting, heading and grain filling growth stages to maintain the corresponding field capacity $(50 \%$ or $75 \%$ or $100 \%$ FC). On the other hand, the precipitation in the second season, which represented an example of good water conditions for wheat production, was $134 \%$ of the long-term average with unfavorable distribution for both seasons at the wheat sensitive growth stages $(73 \mathrm{~mm}$ and $4 \mathrm{~mm}$ during March and April of the first season and $22 \mathrm{~mm}$ and $60 \mathrm{~mm}$ during the same months of the second season). Moreover, about $77 \%$ and $83 \%$ of seasonal rainfall have taken place between October and February, while $23 \%$ and $17 \%$ fell between March and May for the two seasons, respectively. We know that competition for restrictive assimilates, chiefly water, between vegetative and reproductive organs may arise for wheat, during March and May in particular [24,25]. Moreover, in the second season the distribution of rainfall was sufficient for maintaining the full field capacity. Therefore, water was applied twice during the second season in small amounts: $11 \mathrm{~mm}$ during booting on March 2015, and $20.6 \mathrm{~mm}$ during late grain filling on May 2015, which implies that the crop was receiving water during the most sensitive growth stages to water stress with respect to gain yield. The average air temperature at Maru station was generally cooler in the second season. However, the maximum temperature at GS61 (April) of the second season was more than $30^{\circ} \mathrm{C}$ but the crop was unaffected due to good soil moisture reserves.

\subsection{Effect of Supplemental Irrigation on Yield Components}

The yield components, including spikes $\mathrm{m}^{-2}$, grains spike ${ }^{-1}$, and TGW, were found to increase with improving soil moisture. This trend was very clear in the first season, where a gradual increase in number of spikes was observed with increasing soil water content. The spike number increased by up to $50 \%$ when maintaining full soil field capacity. Richards et al. [25] indicated that water deficit conditions during the different growth and developmental stages decreased spikes $\mathrm{m}^{-2}$, floret fertility, and consequently grains spike ${ }^{-1}[23-25]$.

Indeed, greater grains spike ${ }^{-1}$ in response to increased water availability in the soil was demonstrated in this study. In the first season, all the SI levels applied produced more grains than did the rain-fed treatment. The highest and significant grains number (40.77) was produced by maintaining soil moisture at full FC. On the other hand, the highest number of grains (38.78) in the second season did not significantly differ from rain-fed conditions (control) even when SI maintained water content at the full FC. The lower number of grains spike ${ }^{-1}$ in the rain-fed treatment could be attributed to limited water availability at booting stage when the number of grains was determined. Reduced grains spike $^{-1}$ due to sever competition among the plant organs for assimilates during stem elongation was 
reported in many studies (e.g., [23,25,42]). In addition, it has been reported that water stress during reproductive development stages decreased grain yield compared with the control through a reduction in number of fertile tillers and grains spike ${ }^{-1}[55]$.

TGW was also improved by enhancing water condition as revealed in this study. In the first season, TGW was found to be increasing as water in the soil increased with the highest and most significant value (42.18) occurring at the full FC. In the second season, the highest value of full FC was not significantly different to the control treatment. It has been reported that water deficit at post-anthesis decreased grain filling period, grain weight, and crop production [60,61]. On the other hand, Zhang and Oweis [62] and Hu et al. [63] reported better yield components such as TGW, grain weight spike ${ }^{-1}$ and number of grains per unit area obtained by improving soil moisture up to $50-75 \%$ of FC. Del Moral [23] demonstrated that grains spike ${ }^{-1}$ has a significant contribution to grain yield, mainly under drought conditions (the first season of the current study), while in cooler environments (the second season) the compensatory effects among yield components were almost absent, probably because of the relative availability of water during the critical stages of wheat development.

\subsection{Effect on Grain Yield, Above-Ground Biomass, and Harvest Index}

The ability of a cultivar to produce satisfactory yield over a wide range of stress and non-stress environments is critical, since the ideal genotype should result in a high yield under stress as well as under optimum growing conditions [38]. The results of this study clearly indicated the positive effect of SI on grain yield. Applying supplemental water from $84 \mathrm{~mm}$ to $157.9 \mathrm{~mm}$ in 2014 increased the yield compared to the rain-fed conditions from $70 \%$ to $113.5 \%$. In the season (2014), water was applied to compensate for water shortage during the sensitive growth stages such as booting and grain filling. As water availability increased, grain yield also increased with maintaining the crop at the full FC resulting in the highest yield. The second season (2015), which had good water conditions for wheat production, significant increase in grain yield compared to the rain-fed conditions was achieved only by maintaining full FC, which only required an additional $31 \mathrm{~mm}$ of water. However, this small supplemental amount of water still represented a significant yield increase of $10 \%$ compared to the rain-fed treatment (T0). Similarly, seasonal variations, including rainfall, generated a significant variation in yield, as previously observed [63].

Current results showed that the increase in yield was remarkable even when rainfall was higher than $500 \mathrm{~mm}$ as was the case in 2015. The increase in yield due to improving water availability to wheat crop was also demonstrated in many studies [64-69].

Furthermore, the reduction in grain yield under the rain-fed treatment in the current study could be attributed to the findings of Saidi et al. [70], who showed that a significant reduction in grain yield in rain-fed conditions may result from reducing the production of photo-assimilates for grain filling, reducing the sink power in absorbing photo-assimilates and reducing the grain filling duration. Obviously, water stress hastens maturation and decreases photosynthesis, leading to lower grain yield.

The present results indicated that AGBM increased as water availability increased. The improvement in water conditions implied by different levels of SI led to a significant increase in AGBM compared to the rain-fed conditions by $35 \%$ for T1 to $56 \%$ for T3 in the first season. On the other hand, results of the second season showed no significant differences in AGBM between the rain-fed and the SI because of applying relatively small water amounts to reach the FC (31 mm). The $10 \%$ increase in grain yield in the second season could be due to the time of water application in the most sensitive growth stages for grain yield; at booting stage where the number of grains was determined, and at grain filling stage where photo-assimilates were transported to grains. Wang et al. (2005) [26] showed that when water deficit occurred at the tillering, elongation, or grain filling stages, it resulted in a decreased AGBM and grain yield.

On the other hand, the current study showed that SI at the stem elongation stage could positively affect grain yield compared to the rain-fed cultivars. In fact, water is essential at every stage of plant growth and development, from seed germination to plant maturation, but sensitivity of wheat to water 
stress increased as the plant growth progressed and reached its maximum during the early dough stage [71].

HI was also increased with increasing water availability compared to the rain-fed cultivars. In the first season, 75\% FC resulted in the highest HI values, while in the second season, adding $31 \mathrm{~mm}$ significantly led to higher $\mathrm{HI}$ values compared to the rain-fed cultivars. These results were similar to those of Van den Boogaard et al. [72], who found a reduction in HI values under water stress conditions. Our findings were consistent with Wajid et al. [66], who reported that a controlled soil water content can improve HI [68].

\subsection{Water Use Efficiency (WUE) $\left(\mathrm{kg} \mathrm{m}^{-3}\right)$}

Our study revealed that the effect of WUE on grain yield was improved by adding water. This was clear in the first season, when by adding $157 \mathrm{~mm}$ the grain yield was doubled. This study pointed out that limited water conditions, as experienced in the first season under rain-fed conditions, reduced the WUE of grain yield, whereas maintaining the field capacity at $50 \%$, at least at all growth stages, improved both grain yield and WUE. In fact, the improvement of WUE with SI was reported in many studies [33,62].

\subsection{Total Chlorophyll Content (TCC) and Canopy Temperature Depression (CTD)}

The present study strongly highlighted the importance of optimum water conditions on improving the physiological status of the crop as revealed from the values of TCCCTD. It has been shown that CTD relative to ambient air temperature is an indication of how efficient the transpiration is in cooling the leaves under a given environmental stress condition.

Current investigation indicated that increasing water availability increased chlorophyll content especially at post-anthesis where water uptake rate was relatively very high. In fact; TCC is an important factor in determining the photosynthetic rate and dry mater production [73-75]. The pronounced effect of water levels on TCC at post-anthesis might be due to the changes in photosynthetic rate, which is parallel to the change of chlorophyll content during grain filling [76].

The improvement in CTD values as related to water availability was also shown in this study. Results showed that values of CTD increased by maintaining wheat crop, at all growth stages, at least at $50 \%$ of FC in comparison with rain-fed conditions. In agreement, values of CTD at completion of anthesis and chlorophyll content in grain filling stage showed significant differences [29]. Saxena et al. [28] concluded that CTD and TCC might play an effective role in identifying drought tolerant genotypes. In addition, high CTD scores at different growth stages in the current study implied that CTD can be used as an important selection parameter that help in reducing the evapotranspiration of the soil moisture and increase grain yield. Furthermore, cooler canopies with SI reflected an increase in transpiration resulting from stomatal opening [77].

\subsection{Correlation among Characteristics}

Correlation analysis among characteristics across the two seasons and the four water regimes revealed that grain yield is significantly correlated with all investigated characteristics (Table 6), which in turn was found to be improved by optimal water conditions. Grain yield was positively correlated with different yield components. These findings were consistent with Shamsuddin [78], who reported that spikes plant $^{-1}$, grains spike ${ }^{-1}$, TGW, HI, glumes weight and AGBM were directly related to grain yield. Koocheki et al. [79] and Farnia and Tork [80] indicated that increasing grain weight is accompanied by increasing HI. Moreover, it has been reported that grains spike ${ }^{-1}$ and grain weight had significantly positive effects on grain yield under moisture stress conditions [81,82], as well as under well-watered conditions [80].

Data revealed strong correlation between both CTD and TCC with grain yield. Our results were consistent with previous findings $[73,83,84]$ that indicated that there was a linear, positive correlation between chlorophyll content and grain yield. They found that low chlorophyll content caused lower 
photosynthetic rate and consequently low grain yield. Similarly, Olivares-Villegas et al. [34] showed a positive correlation of CTD with grain yield. The current study showed that CTD and TCC have strong positive correlations with most of the measured traits. Similar findings were reported by Khakwani et al. [85]. Moreover, it was reported that CTD and TCC were positively correlated with many physiological adaptive traits $[30,31,35,36]$. This put CTD and TCC among the main traits that can be targeted by plant breeders to improve wheat production in Jordan.

Our study indicated that all varieties produced higher grain yield under increased soil moisture as compared to the rain-fed treatment. However, the wheat cultivars tested showed significant differences for most characteristics investigated across the four water regimes. In each water condition and across the two seasons, the Ammon variety had the highest grain yield. The superiority of Ammon in grain yield was accompanied by its higher HI, spikes $\mathrm{m}^{-2}$ and grains spike ${ }^{-1}$. Such differences in grain yield are primarily attributed to the different tillering potential of the wheat cultivars tested.

On the other hand, both Ammon and Cham1 had higher WUE for grain yield than Acsad65. Acsad65, in turn, had the highest TGW, while Ammon found to have lower TGW but compensated for it by producing more spikes and grains spike ${ }^{-1}$. This finding expresses the negative relationship between grain number and grain weight (i.e., Ammon produced more grains but with lower grain weight, while Acsad65 produced fewer grains but of heavier weight). Based on the grain yield evaluation of all tested cultivars, Ammon was ranked first followed by Cham1 then Acsad65. Our results revealed the superiority of Ammon cultivar, a bread cultivar, over the other two durum wheat cultivars despite the fact that durum type has long been known for its higher grain yield and yield components [86]. This cultivar was found to have the lowest thermal time to maturity, enabling it to avoid terminal high temperatures. In addition, Ammon had the highest values of both CTD and TCC, which were strongly correlated with grain yield.

Both CTD and TCC at post-anthesis showed a positive, linear correlation with grain yield in the three cultivars under the four water regimes tested (Figures 4 and 5). This correlation was consistent with Fan et al. [87], who demonstrated that regression results for CTD and yield suggested that the best time for taking CTD measurement for grain yield evaluation was 3-4 weeks after heading in irrigated crops but any time before senescence in rain-fed crops. Consistent with our findings, it has been suggested that the SPAD value measurement at the medium milky stage is a reliable indicator for screening drought-tolerant genotypes, due to the higher relationships between TCC and grain yield components [88].

\section{Conclusions}

In both growing seasons, irrigation regime is the principal limiting factor for grain yield. Results indicated that normal distribution of monthly precipitation, especially during the spring months, may positively affect grain yield of wheat rather than total seasonal rainfall. Analyses of variance for grain yield and yield components demonstrated that these traits were highly affected by SI. In fact, the effects of irrigation regimes were pronounced for the majority of the traits studied. On the other hand, grain yield was higher in the cooler than in the warmer season as a consequence of more grains $\mathrm{m}^{-2}$, heavier grains, and a longer life cycle. Rain-fed conditions caused reductions in grain yield, estimated at $48 \%$ and $9 \%$ for the first and second seasons, respectively, in comparison with irrigation treatments. In the first season (dry), wheat had the greatest yield with SI at $100 \% \mathrm{FC}$, after which yield decreased significantly, with SI at 75\% and 50\% FC. In the second season (wet), the results showed that yield was not affected by the amount of water added. Effects acquired in this study showed that the degree of yield decrease may depend on weather conditions during the growing season. These different yield responses to irrigation for the three spring wheat cultivars in the first season were probably related to little rainfall (especially in spring) coupled with poor distribution. Indeed, Loss and Siddique [52], Passioura [89] and Del Pozo et al. [90] showed that the best yield was produced when SI matches plant growth and water demand, while Rasmussen et al. reported that yield was commonly greater if rainfall was partially distributed during the spring months, predominantly in May 
and June. To avoid a possible decline in yield with small rainfall amounts in spring months, SI supply during this stage of the crop growth was found to regulate and stabilize yield under the Mediterranean conditions of northern Jordan. Acsad65 yielded less than Ammon under the same climatic conditions and cultural practices, which was particularly significant in the production of grains $\mathrm{m}^{-2}$. The reason for the lower yield in Acsad65 may be that this cultivar is considered a drought-tolerant cultivar, and therefore its reaction to water was not obvious due to the confusing effects of genotype and the physiological mechanisms of tolerance of this cultivar. For the same water supply levels, Ammon had significantly higher WUE values than Acsad65. SI significantly influenced WUE in the first season and slightly in the second season. Also, wheat cultivars responded differently to the irrigation regime; Ammon appeared to be more sensitive than Acsad65.

In general, it has been pointed out that wheat cultivars exposed to drought stress are able to flower earlier and, hence, bring the grain filling period forward, helping the plants to avoid the adverse effects of the drought and harsh climate [8,91,92]. This study suggested that the use of CTD and SPAD as appropriate selection criteria for breeding programs in Jordan is extremely useful since both parameters showed highly positive correlation with grain yield and significant variations existed with respect to the cultivars and water regimes applied. Indeed, the current study suggested that improved cultivars and wise water management can play an important role inthe stability of wheat production, meeting the needs of an increasing population, and coping with climate change in Jordan and in the whole world.

Author Contributions: A.L.A.A.-G. initiated, designed, and managed the experiments, and significantly contributed to the manuscript preparation and the interpretation and analysis of the results. Y.B.K. designed and managed the experiments at Maru Station, collected the data, and helped with preparing the manuscript. Z.I.A.-A. significantly contributed to data analysis and the interpretation of the results and discussion. N.A.A.-Q. and I.M. significantly contributed to the realization of the study, data availability, and the interpretation of the results. N.B.H. contributed to the design of the study. All authors have read and approved the final manuscript.

Acknowledgments: We gratefully acknowledge the Deanship of Scientific Research (Research \#20160188), Jordan University of Science and Technology, and ICARDA for financial support.

Conflicts of Interest: The authors declare no conflict of interest.

\section{References}

1. Edwards, M.A. Morphological Features of Wheat Grain and Genotype Affecting Flour Yield. Ph.D. Thesis, Southern Cross University, Lismore, NSW, Australia, 2010.

2. Mirbahar, A.A.; Markhand, G.S.; Mahar, A.R.; Abro, S.A.; Kanhar, N.A. Effect of water stress on yield and yield components of wheat (Triticum aestivum L.) varieties. Pak. J. Bot. 2009, 41, 1303-1310.

3. Tadesse, W.; Solh, M.; Braun, H.J.; Oweis, T.; Baum, M. Approaches and Strategies for Sustainable Wheat Production: Tools and Guidelines; ICARDA: Beirut, Lebanon, 2016; ISBN 92-9127-490-9.

4. Lucas, H. Wheat Initiative: An International Vision for Wheat Improvement. 2013. Available online: www.wheatinitiative.org (accessed on 31 March 2014).

5. Gautam, A.; Sai Prasad, S.V.; Jajoo, A.; Ambati, D. Canopy temperature as a selection parameter for grain yield and its components in durum wheat under terminal heat stress in late sown conditions. Agric. Res. 2015, 4, 238-244. [CrossRef]

6. GCARD. Breakout session P1.1. National Food Security-The Wheat Initiative-An International Research Initiative for Wheat Improvement. In Proceedings of the 2nd Global Conference on Agricultural Research for Development, Punta del Este, Uruguay, 29 October-1 November 2012.

7. Loggini, B.; Scartazza, A.; Brugnoli, E.; Navari-Izzo, F. Antioxidative defense system, pigment composition, and photosynthetic efficiency in two wheat cultivars subjected to drought. Plant Physiol. 1999, 1091-1099. [CrossRef]

8. Varga, B.; Vida, G.; Varga-La'szlo', E.; Bencze, S.; Veisz, O. Effect of simulating drought in various phenophases on the water use efficiency of winter wheat. J. Agro Crop Sci. 2015, 201, 1-9. [CrossRef]

9. Jordan Department of Statistics. Plant Production Report. Available online: http://www.dos.gov.jo/sdb/ sdb_pop/sdb_pop_a/index_o.htm2015 (accessed on 15 April 2016). 
10. Dixit, P.; Telleria, R.; Al Khatib, A.N.; Allouzi, S.F. Decadal analysis of impact of future climate on wheat production in dry Mediterranean environment: A case of Jordan. Sci. Total Environ. 2018, 610-611, 219-233. [CrossRef] [PubMed]

11. IPCC. Impacts, Adaptation and Vulnerability: Contribution of Working Group II to Fourth Assessment Report of the Intergovernmental Panel on Climate Change; Cambridge University Press: Cambridge, UK, 2007.

12. Schiermeier, Q. Water: A long dry summer. Nature 2008, 452, 270-273. [CrossRef] [PubMed]

13. Al-Ajlouni, Z.I.; Al-Abdallat, A.; Al-Ghzawi, A.; Ayad, J.; Abu Elenein, J.; Al Quraan, N.; Baenziger, P.S. Impact of pre-anthesis water deficit on yield and yield components in barley (Hordeum vulgare L.) plants grown under controlled conditions. Agronomy 2016, 6, 33. [CrossRef]

14. Trethowan, R.M.; Maarten, V.G.; Rajaram, S. Progress in breeding wheat for yield and adaptation in global drought affected environments. Crop Sci. 2002, 42, 1441-1446. [CrossRef]

15. Peltonen-Sainio, P.; Kangas, A.; Salo, Y.; Jauhiainen, L. Grain number dominates grain weight in temperate cereal yield determination: Evidence based on30 years of multi-location trials. Field Crop. Res. 2007, 100, 179-188. [CrossRef]

16. Abou El-Kheir, M.S.A.; Kandil, S.A.; El-Zeiny, H.A. Response of some wheat cultivars to water stress imposed at certain growth stages. Egy. J. App. Sci. 2001, 16, 82-98.

17. Sharaan, A.N.; Abd El-Samie, F.S.; Abd El-Gawad, I.A. Effect of planting date and drought at different plant stages on yield and its components. In Response of Wheat Varieties (Triticum aetivum L.) to Some Environmental Influences, Proceedings of the 9th Conference of Agronomy, 1-2 September 2000; Minuofiya University: Minuofiya, Egypt, 2000.

18. Kumar, A.; Azam-Ali, S.N.; Snape, J.W.; Weightman, R.; Foulkes, M.J. Relationships between carbon-isotope discrimination and grain yield in wheat under well-watered and drought conditions. J. Agric. Sci. Camb. 2011, 149, 257-272. [CrossRef]

19. Mirza, M.M.Q. Climate change, flooding in South Asia and implications. Reg. Environ. Chang. 2011, 11, 95-107. [CrossRef]

20. Calderini, D.F.; Reynolds, M.P.; Slafer, G.A. Genetic gains in wheat yield and main physiological changes associated with them during the 20th century. In Wheat: Ecology and Physiology of Yield Determination; Satorre, E.H., Slafer, G.A., Eds.; Food Products Press: New York, NY, USA, 1999; pp. 351-377.

21. Kilic, H.; Yağbasanlar, T. The effect of drought stress on grain yield, yield components and some quality traits of durum wheat (Triticum turgidum ssp. durum) cultivars. Not. Bot. Horti Agrobo. 2010, 38, 164-170.

22. Shpiler, L.; Blum, A. Heat tolerance to yield and its components in different wheat cultivars. Euphytica 1991, 51, 257-263. [CrossRef]

23. Garcia Del Moral, L.F.; Ramos, J.M.; Garcia Del Moral, M.B.; Jimenez-Tejada, P. Ontogenetic approach to grain production in spring barley based on path-coefficient analysis. Crop Sci. 1991, 31, 1179-1185. [CrossRef]

24. Maqbool, M.M.; Ali, A.; Haq, T.; Majeed, M.N.; Lee, D.J. Response of spring wheat (Triticum aestivum L.) to induced water stress at critical growth stages. Sarhad J. Agric. 2015, 31, 53-58.

25. Richards, R.A.; Condon, A.G.; Rebetzke, G.J. Traits to improve yield in dry environments. In Application of Physiology in Wheat Breeding; Reynolds, M.P., Ortiz-Monasterio, J.I., McNab, A., Eds.; CIMMYT: Mexico, 2001; pp. 88-100, ISBN 970-648-077-3.

26. Wang, Z.; Li, S.; Vera, C.L.; Malhi, S.S. Effects of water deficit and supplemental irrigation on winter wheat growth, grain yield and quality, nutrient uptake, and residual mineral nitrogen in soil. Commun. Soil Sci. Plant Anal. 2005, 36, 1405-1419. [CrossRef]

27. Chahbar, S.; Belkhodja, M. Water deficit effects on morpho-physiological parameters in durum wheat. J. Fundam. Appl. Sci. 2016, 8, 1166-1181. [CrossRef]

28. Saxena, D.C.; Sai Prasad, V.; Chatrath, R.; Mishra, S.C.; Watt, M.; Prashar, R.; Wason, A.; Gautam, A.; Malviya, P. Evaluation of root characteristics, canopy temperature depression and stay green trait in relation to grain yield in wheat under early and late sown conditions. Indian J. Plant Physiol. 2014, 19, $43-47$. [CrossRef]

29. Shefazadeh, M.; Karimizadeh, R.; Mohammadi, M.; Suq, H.S. Using flag leaf chlorophyll content and canopy temperature depression for determining drought resistant durum wheat genotypes. Food Agric. Environ. 2012, 10, 509-515. 
30. Reynolds, M.P.; Mujeeb-Kazi, A.; Sawkins, M. Prospects for utilizing plant-adaptive mechanisms to improve wheat and other crops in drought- and salinity-prone environments. Ann. Appl. Biol. 2005, 146, 239-259. [CrossRef]

31. Davies, K.F.P.; Chesson, S.; Harrison, B.D.; Inouye, B.; Melbourne, A.; Rice, K.J. Spatial heterogeneity explains the scale dependence of the native-exotic diversity relationship. Ecology 2005, 86, 1602-1610. [CrossRef]

32. Othmani, A.; Rezgui, M.; Cherif, S.; Mouelhi, M.; Melki, M. Effects of water regimes on root and shoot growth parameters and agronomic traits of Tunisian durum wheat (Triticum durum Desf.). J. New Sci. Agric. Biotechnol. 2015, 18, 695-702.

33. Man, J.; Shi, Y.; Yu, Z.; Zhang, Y. Root growth, soil water variation, and grain yield response of winter wheat to supplemental irrigation. Plant Prod. Sci. 2016, 19, 193-205. [CrossRef]

34. Olivares-Villegas, J.J.; Reynolds, M.P.; McDonald, G.K. Drought-adaptive attributes in the Seri Babax hexaploid wheat population. Funct. Plant Biol. 2007, 34, 189-203. [CrossRef]

35. Fokar, M.; Nguyen, H.; Blum, A. Heat tolerance in spring wheat I. Estimating cellular thermo-tolerance and its heritability. Euphytica 1998, 104, 1-8. [CrossRef]

36. Fotovat, R.; Valizadeh, M.; Toorchi, M. Association between water-use-efficiency components and total chlorophyll content (SPAD) in wheat (Triticum aestivum L.) under well-watered and drought stress conditions. J. Food Agric. Environ. 2007, 5, 225-227.

37. Condon, A.G.; Richards, R.A.; Rebetzke, G.J.; Farquhar, G.D. Improving intrinsic water-use efficiency and crop yield. Crop Sci. 2002, 42, 122-131. [CrossRef] [PubMed]

38. Kirigwi, F.M.; Van Ginkel, M.; Trethowa, R.; Sears, R.G.; Rajaram, S.; Paulsen, G.M. Evaluation of selection strategies for wheat adaptation across water regimes. Euphytica 2004, 135, 361-371. [CrossRef]

39. Saadi, S.; Todorovic, M.; Tanasijevic, L.; Pereira, L.S.; Pizzigalli, C.; Lionello, P. Climate change and Mediterranean agriculture: Impacts on winter wheat and tomato crop evapotranspiration, irrigation requirements and yield. Agric. Water Manag. 2015, 147, 103-115. [CrossRef]

40. Heng, L.K.; Asseng, S.; Mejahed, K.; Rusan, M. Optimizing wheat productivity in two rain-fed environments of the West Asia-North Africa region using a simulation model. Eur. J. Agron. 2007, 26, 121-129. [CrossRef]

41. Oweis, T.Y.; Hachum, A.Y. Improving water productivity in the dry areas of west Asia and North Africa. In Water Productivity in Agriculture: Limits and Opportunities for Improvement; Kijne, J.W., Barker, R., Molden, D., Eds.; CABI Publishing and International Water Management Institute: Wallingford, UK, 2003.

42. Semcheddine, N.; Hafsi, M. Effect of supplementary irrigation on agronomical and physiological traits in durum wheat (Triticum durum desf.) genotypes. J. Agric. Sci. 2014, 6, 184-198. [CrossRef]

43. Allouzi, S.; Al-Karadsheh, I.; Al-Hoyan, M.; Rawashdeh, I.; Al-Kaabenah, A. Phenotypic Variation and Genetic Variation of Certified Wheat Varieties in Jordan; Project of NCARE 2007-2010; National Center for Agricultural Research and Extension (NCARE): Amman, Jordan, 2010.

44. Allouzi, S.; Al Rawashdeh, I.M. Screening of Jordan Certified Wheat Seedlings for Drought Tolerance. Jordan J. Agric. Sci. 2014, 10, 484-492.

45. Dubey, R.P.; Kalubarme, M.H.; Jhorar, O.P.; Cheema, S.S. Wheat Yield Models and Production Estimates for Patiala and Ludhiana Districts Based on Lands at-MSS and Agro Meteorological Data; Scientific Note: IRS-UP/SAC/CPF/SN/08/87; Space Applications Centre: Ahmedabad, India, 1987; pp. 1-34.

46. Sharma, A.; Sood, R.K.; Kalubarme, M.H. Agro meteorological wheat yield forecast in Himachal Pradesh. J. Agrometeorol. 2004, 6, 153-160.

47. Tottman, D.R.; Broad, H. Thedecimal code for the growth stages of cereals with illustrations. Ann. Appl. Biol. 1987, 93, 221-234. [CrossRef]

48. Marquard, R.D.; Tipton, J.L. Relationship between extractable chlorophyll and an in situ method to estimate leaf greenness. Hort. Sci. 1987, 22, 1327.

49. Steel, R.G.D.; Torrie, J.H. Principle and Procedure of Statistics: A Biometrical Approach, 2nd ed.; McGraw-Hill: New York, NY, USA, 1980; p. 633, ISBN 0070609268.

50. Karam, F.; Kabalan, R.; Breidi, J.; Rouphael, Y.; Oweis, T. Yield and water production functions of two durum wheat cultivars grown under different irrigation and nitrogen regimes. Agric. Water Manag. 2009, 96, 603-615. [CrossRef]

51. Slafer, G.A.; Araus, J.L.; Royo, C.; Garcia Del Moral, L.F. Promising eco-physiological traits for genetic improvement of cereal yields in Mediterranean environments. Ann. Appl. Biol. 2005, 146, 61-70. [CrossRef] 
52. Loss, S.P.; Siddique, K.H.M. Morphological and physiological traits associated with wheat yield increases in Mediterranean environments. Adv. Agron. 1994, 52, 229-276.

53. Miranzadeh, H.; Emam, Y.; Seyyed, H.; Zare, S. Productivity and radiation use efficiency of four dryland wheat cultivars under different levels of nitrogen and chlormequat chloride. J. Agric. Sci. Technol. 2011, 13, 339-351.

54. Mwadzingeni, L.; Shimelis, H.; Dube, E.; Laing, M.D.; Tsilo, T.J. Breeding wheat for drought tolerance: Progress and technologies. J. Integr. Agric. 2016, 15, 935-943. [CrossRef]

55. Ciadir, G.; Saeed, M.; Cheema, M.A. Effect of water stress on growth and yield performance of four wheat cultivars. Pak. J. Biol. Sci. 1999, 2, 236-239.

56. Campbell, C.A.; Read, D.W.L.; Zentner, R.P.; Leyshon, A.J.; Ferguson, W.S. First 12 years of a long-term crop rotation study in southwestern Saskatchewan-yield and quality of grain. Can. J. Plant Sci. 1983, 63, 91-108.

57. Oweis, T.; Pala, M.; Ryan, J. Management alternatives for improved durum wheat production under supplemental irrigation in Syria. Euro. J. Agron. 1999, 11, 225-266. [CrossRef]

58. Oweis, T. Supplemental Irrigation: A Highly Water-Efficient Practice; ICARDA: Alleppo, Syria, 1997; ISBN 92-9127-070-9.

59. Blum, A.; Pnuel, Y. Physiological attributes associated with drought resistance of wheat cultivars in a Mediterranean environment. Aust. J. Agric. Res. 1990, 41, 799-810. [CrossRef]

60. Donaldson, E. Crop traits for water stress tolerance. Am. J. Altern. Agric. 1996, 11, 89-94. [CrossRef]

61. Nazeri, M. Study on Response of Triticale Genotypes at Water Limited Conditions at Different Developmental Stages. Ph.D. Thesis, University of Tehran, Tehran, Iran, 2005.

62. Zhang, H.; Oweis, T. Water-yield relations and optimal irrigation scheduling of wheat in the Mediterranean region. Agric. Water Manag. 1999, 38, 195-211. [CrossRef]

63. Hu, C.; Ding, M.; Qu, C.; Sadras, V.; Yang, X.; Zhang, S. Yield and water use efficiency of wheat in the Loess Plateau: Responses to root pruning and defoliation. Field Crops Res. 2015, 179, 6-11. [CrossRef]

64. Oweis, T. On-farm water management: From efficiency to productivity. In Proceedings of the Training Course on Improving Water Productivity in Agricultural Systems, Amman, Jordan, 6-24 May 2012.

65. Hussain, A.; Ghaudhry, M.R.; Wajad, A.; Rafiq, M.; Ibrahim, M.; Goheer, A.R. Influence of water stress on growth, yield and radiation use efficiency of various wheat cultivars. Int. J. Agric. Biol. 2004, 6, 1074-1079.

66. Wajid, A.; Hussain, A.; Ahmed, A.; Rafiq, M.; Goheer, A.R.; Ibrahim, M. Effect of sowing date and plant density on growth, light interception and yield of wheat under semi-arid condition. Int. J. Agric. Biol. 2004, 6, 1119-1123.

67. Li, Q.S.; Willardson, L.S.; Deng, W.; Li, X.J.; Liu, C.J. Crop water deficit estimation and irrigation scheduling in western Jilin province, Northeast China. Agric. Water Manag. 2004, 71, 47-60. [CrossRef]

68. Kang, S.; Zhang, L.; Liang, Y.; Hu, X.; Cai, H.; Gu, B. Effects of limited irrigation on yield and water use efficiency of winter wheat in the Loess Plateau of China. Agric. Water Manag. 2002, 55, 203-216. [CrossRef]

69. Wajid, A.; Hussain, A.; Maqsood, M.; Ahmad, A.; Awais, M. Influence of sowing date and irrigation levels on growth and grain yield of wheat. Pak. J. Agric. Sci. 2002, 39, 22-24.

70. Saidi, Y.; Peter, P.; Finka, A.; Cicekli, C.; Vígh, L.; Goloubinoff, P. Membrane lipid composition affects plant heat sensing and modulates $\mathrm{Ca}^{2+}$-dependent heat shock response. Plant Signal. Behav. 2010, 5, 1530-1533. [CrossRef] [PubMed]

71. Tadayon, M.R.; Ebrahimi, R.; Tadayon, A. Increased water productivity of wheat under supplemental irrigation and nitrogen application in a semi-arid region. J. Agric. Sci. Technol. 2012, 14, 995-1003.

72. Van den Boogaard, R.; Veneklaas, E.J.; Lambers, H. The association of biomass allocation with growth and water use efficiency of two Triticum aestivum cultivars. Aust. J. Plant Physiol. 1996, 23, 751-761. [CrossRef]

73. Bijanzadeh, E.; Emam, Y. Effect of defoliation and drought stress on yield components and chlorophyll content of wheat. Pak. J. Biol. Sci. 2010, 13, 699-705. [CrossRef] [PubMed]

74. Ghosh, P.K.; Ajay, K.K.; Bandyopadhyay, M.C.; Manna, K.G.; Mandal, A.K.; Hati, K.M. Comparative effectiveness of cattle manure, poultry manure, phosphor-compost and fertilizer-NPK on three cropping system in vertisols of semi-arid tropics: Dry matter yield, nodulation, chlorophyll content and enzyme activity. Biores. Technol. J. 2004, 95, 85-93. [CrossRef] [PubMed]

75. Nezhadahmadi, A.; Prodhan, Z.H.; Faruq, F. Drought tolerance in wheat. Sci. World J. 2013, 2013, 1-12. [CrossRef] [PubMed] 
76. Guendouz, A.; Maamari, K. Grain filling, chlorophyll content in relation with grain yield component of durum wheat in a Mediterranean environment. Afr. Crop Sci. J. 2012, 20, 31-37.

77. Siddique, R.B.; Hamid, A.; Islam, M.S. Drought stress effects on water relations of wheat. Bot. Bull. Acad. Sin. 2000, 41, 35-39.

78. Shamsuddin, A.K.M. Path analysis in bread wheat. Indian J. Agric. Sci. 1987, 1, 237-240.

79. Koocheki, A.R.; Yazdansepas, A.; Nikkhah, H.R. Effects of terminal drought on grain yield and some morphological traits in wheat (Triticum aestivum L.) genotypes. Iran J. Agric. Sci. 2006, 8, 14-29.

80. Farnia, A.; Tork, A. Changes in Yield and yield components of wheat cultivars under water stress condition. Int. J. Life Sci. 2015, 9, 103-107. [CrossRef]

81. Simane, B.; Struik, P.C.; Nachit, M.M.; Peacock, J.M. Onto-genic analysis of field components and yield stability of durum wheat in water-limited environments. Euphytica 1993, 71, 211-219. [CrossRef]

82. Erchidi, A.E.; Benbella, M.; Talouizte, A. Grain growth in nine durum cultivars: Options Mediterranean's Serie A. Semin. Mediterr. 2003, 40, 137-140.

83. Zaharieva, M.; Gaulin, E.; Havaux, M.; Acevedo, E.; Monnevaux, P. Drought and heat responses in the wild wheat relative Aegilopsgeniculata Roth. Crop Sci. 2001, 41, 1321-1329. [CrossRef]

84. Karimizadeh, R.; Mohammadi, M.; Ghaffaripour, S.; Karimpour, F.; Shefazadeh, M.K. Evaluation of physiological screening techniques for drought resistant breeding of durum wheat Genotypes in Iran. Afr. J. Biotechnol. 2011, 10, 12107-12117.

85. Khakwani, A.; Dennett, M.D.; Munir, M.; Abid, M. Growth and yield response of wheat varieties to water stress at booting and anthesis stages of development. Pak. J. Bot. 2012, 44, 879-886.

86. Fischer, R.A.; Maurer, R. Drought resistance in spring wheat cultivars. I. Grain yield responses. Aust. J. Agric. Res. 1978, 29, 897-912. [CrossRef]

87. Fan, T.; Wang, S.; Xiaoming, T.; Luo, J.; Stewart, B.A.; Gao, Y. Grain yield and water use in a long-term fertilization trail in Northwest China. Agric. Water Manag. 2005, 76, 36-52. [CrossRef]

88. Abdipur, M.; Ramezani, H.R.; Bavei, V.; Talaee, S.; Branch, G. Effectiveness of canopy temperature and chlorophyll content measurements at different plant growth stages for screening of drought tolerant wheat genotypes. Am. Eurasian J. Agric. Environ. Sci. 2013, 13, 1325-1338.

89. Passioura, J.B. Roots and drought resistance. Agric. Water Manag. 1983, 7, 265-280. [CrossRef]

90. Del Pozo, A.; Yáñez, A.; Matus, I.A.; Tapia, G.; Castillo, D.; Sanchez-Jardón, L.; Araus, J.L. Physiological traits associated with wheat yield potential and performance under water-stress in a Mediterranean environment. Front. Plant Sci. 2016, 7, 987. [CrossRef] [PubMed]

91. Dixon, L.; Karsai, I.; Allard, V.; Griffiths, S.; Boden, S. A genetic mechanism for adaptation of wheat to variable growth temperatures. In Proceedings of the 13th International Wheat Genetics Symposium, Tulln, Austria, 23-28 April 2017; Buerstmayr, H., Lang-Mladek, C., Steiner, B., Michel, S., Buerstmayr, M., Lemmens, M., Vollmann, J., Grausgruber, H., Eds.; BOKU-University of Natural Resources and Life Sciences, Vienna: Wien, Austria, 2017.

92. Yang, J.C.; Zhang, J.H.; Wang, Z.Q.; Liu, L.J.; Zhu, Q.S. Post-anthesis water deficits enhance grain filling in two line hybrid rice. Crop Sci. 2003, 43, 2099-2108. [CrossRef]

(C) 2018 by the authors. Licensee MDPI, Basel, Switzerland. This article is an open access article distributed under the terms and conditions of the Creative Commons Attribution (CC BY) license (http://creativecommons.org/licenses/by/4.0/). 